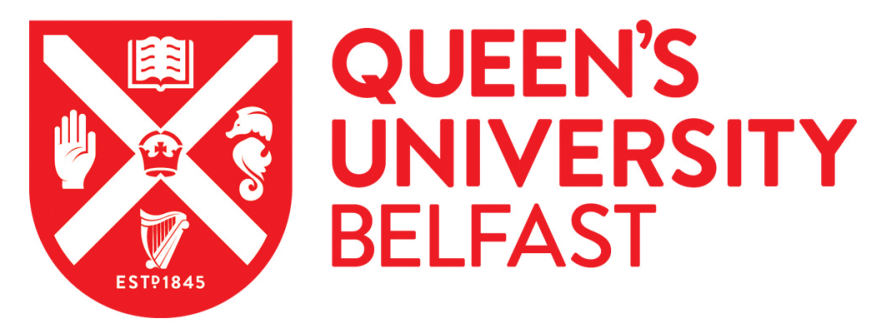

\title{
Optimal design of long-span steel portal frames using fabricated beams
}

McKinstray, R., Lim, J. B. P., Tanyimboh, T. T., Phan, D. T., \& Sha, W. (2015). Optimal design of long-span steel portal frames using fabricated beams. Journal of Constructional Steel Research, 104, 104-114.

https://doi.org/10.1016/j.jcsr.2014.10.010

Published in:

Journal of Constructional Steel Research

Document Version:

Peer reviewed version

Queen's University Belfast - Research Portal:

Link to publication record in Queen's University Belfast Research Portal

Publisher rights

(c) 2015, Elsevier. Licensed under the Creative Commons Attribution-NonCommercial-NoDerivatives 4.0 International

$\mathrm{http}: / /$ creativecommons.org/licenses/by-nc-nd/4.0/ which permits distribution and reproduction for non-commercial purposes, provided the author and source are cited.

\section{General rights}

Copyright for the publications made accessible via the Queen's University Belfast Research Portal is retained by the author(s) and / or other copyright owners and it is a condition of accessing these publications that users recognise and abide by the legal requirements associated with these rights.

Take down policy

The Research Portal is Queen's institutional repository that provides access to Queen's research output. Every effort has been made to ensure that content in the Research Portal does not infringe any person's rights, or applicable UK laws. If you discover content in the Research Portal that you believe breaches copyright or violates any law, please contact openaccess@qub.ac.uk. 


\section{Optimal design of long-span steel portal frames using fabricated}

\section{beams}

Ross McKinstray, James B.P. Lim, Tiku T. Tanyimboh, Duoc T. Phan, Wei Sha*

* Corresponding author

Ross McKinstray: SPACE, David Keir Building, Queen's University, Belfast, BT9 5AG, UK

Email: rmckinstray01@qub.ac.uk

James B.P. Lim: SPACE, David Keir Building, Queen's University, Belfast, BT9 5AG, UK. Email: j.lim@qub.ac.uk

Tiku T. Tanyimboh: Department of Civil and Environmental Engineering, University of Strathclyde, Glasgow, G1 1XJ, UK. Email: tiku.tanyimboh@strath.ac.uk

Duoc T. Phan: Department of Civil Engineering, Universiti Tunku Abdul Rahman, Kuala Lumpur, 53300, Malaysia. Email: phantd@utar.edu.my

Wei Sha: SPACE, David Keir Building, Queen's University, Belfast, BT9 5AG, UK. Email: w.sha@qub.ac.uk

Ross McKinstray, PhD student

James B.P. Lim: PhD, Lecturer

Tiku T. Tanyimboh: PhD, Senior Lecturer

Duoc T. Phan: PhD, Assistant Professor

Wei Sha: PhD, Professor 


\title{
Optimal design of long-span steel portal frames using fabricated
}

\section{beams}

\begin{abstract}
This paper considers the optimal design of fabricated steel beams for long-span portal frames. The design optimisation takes into account ultimate as well as serviceability limit states, adopting deflection limits recommended by the Steel Construction Institute ( $\mathrm{SCl})$. Results for three benchmark frames demonstrate the efficiency of the optimisation methodology. A genetic algorithm (GA) was used to optimise the dimensions of the plates used for the columns, rafters and haunches. Discrete decision variables were adopted for the thickness of the steel plates and continuous variables for the breadth and depth of the plates. Strategies were developed to enhance the performance of the GA including solution space reduction and a hybrid initial population half of which is derived using Latin hypercube sampling. The results show the proposed GA-based optimisation model generates optimal and near-optimal solutions consistently. A parametric study is then conducted on frames of different spans. A significant variation in weight between fabricated and conventional hot-rolled steel portal frames is shown; for a $50 \mathrm{~m}$ span frame, a 14-19\% saving in weight was achieved. Furthermore, since Universal Beam sections in the UK come from a discrete section library, the results could also provide overall dimensions of other beams that could be more efficient for portal frames. Eurocode 3 was used for illustrative purposes; any alternative code of practice may be used.
\end{abstract}

Keywords: hot-rolled steel; fabricated beams; portal frames; genetic algorithms; serviceability limits; buckling limits 


\section{Introduction}

In the UK, it is estimated that steel portal frames account for $90 \%$ of all single-storey buildings [1]. The vast majority of portal frames use hot-rolled steel sections for the column and rafter members. Using such sections, frames economically achieve spans of up to $50 \mathrm{~m}$ [2].

For longer span frames, an alternative to the use of hot-rolled steel sections could be fabricated steel beam sections [3], [4]. Such fabricated beams, built-up through the welding of steel plates, have become increasingly popular for multi-storey buildings, where clear spans of up to $100 \mathrm{~m}$ are achievable [1]. In this paper, the use of such fabricated beams for portal frames will be considered using a genetic algorithm (GA) to size the dimensions of the fabricated beams.

Genetic algorithms have previously been applied to the design optimisation of hot-rolled steel portal frames [5]-[8]. In these studies, only four design variables were used; namely, the cross-section sizes of the columns and rafters, and the length and depth of the eaves haunch [8]. The design used in this present paper was elastic. Phan et al. [8] showed that elastic design was sufficient since the design was controlled by deflection limits.

On the other hand, a design optimisation of fabricated steel sections can involve up to thirteen design variables (see Section 2.2); these being, the dimensions of the plates of each of the members as well as the dimensions of the haunch. To reduce the number of function evaluations, an effective means of enhancing the reliability is required.

Three benchmark frames are considered, with the frames designed elastically under gravity load in accordance with Eurocode 3. Both ultimate and serviceability limit states are considered. A parametric study is conducted to explore the full search space for single story steel buildings. Spans of $14 \mathrm{~m}$ to $50 \mathrm{~m}$ and eave heights varying from $4 \mathrm{~m}$ to $12 \mathrm{~m}$ were considered.

\section{Benchmark frames}

Three frames are considered:

Frame A: Span of $40 \mathrm{~m}$ and height of $10 \mathrm{~m}$ 
Frame B: Span of $50 \mathrm{~m}$ and height of $12 \mathrm{~m}$

Frame C: Span of $60 \mathrm{~m}$ and height of $12 \mathrm{~m}$

The pitch and frame spacing for all three frames are $6^{\circ}$ and $6 \mathrm{~m}$, respectively; such a pitch and frame spacing are typical for portal frames in the UK [2]. The column bases are assumed to be pinned. It is also assumed that the steel sections are fabricated from S275 steel [9].

\subsection{Portal frames composed of universal beams}

Frames are generated by selecting universal beam sections for the column and rafters from a list of 80 standard sections given in the SCl "Steel building design: Design data" Book [10]. The column, rafter and haunch sections are considered as discrete variables with haunch length $\left(\mathrm{H}_{\mathrm{L}}\right)$ treated as a continuous variable [8].

Four universal beam cases (UBC) are considered:

- UBC1 has two decision variables: the column and rafter sections. The haunch is assumed to be the same as the rafter section and haunch length is fixed at $10 \%$ of the span

- UBC2 has three decision variables: column, rafter and haunch sections. The haunch length is fixed at $10 \%$ of the span

- UBC3 also has three decision variables: column section, rafter section and haunch length. The haunch is assumed to be the same as the rafter section.

- UBC4 has four decision variables: column section, rafter section, haunch section and haunch length.

\subsection{Portal frames composed of fabricated beams}

Portal frames composed of fabricated beams are generated with the dimensions described below. The plate thickness is treated as discrete variables and used for the web and flange. 34 plate thicknesses available within the UK are considered; at $1 \mathrm{~mm}$ spacings $6-25 \mathrm{~mm}$; 5 $\mathrm{mm}$ spacings $30-80 \mathrm{~mm}$ and individually $12.5,28$ and $63.5 \mathrm{~mm}$. The depths and breadths of the sections are treated as continuous variables with a range of $110 \mathrm{~mm}$ to $2000 \mathrm{~mm}$ and 50 $\mathrm{mm}$ to $600 \mathrm{~mm}$, respectively.

Three Fabricated Beam Cases (FBC) are considered as follows with 13 decision variables in total: $h_{c}, h_{R}, h_{H}, b_{c}, b_{R}, b_{H}, t_{w c}, t_{w R}, t_{w H}, t_{f c}, t_{f R}, t_{f H}$, and $H_{L}$. The notations use standard 
(descriptive) terminology: $\mathrm{h}$ for height, $\mathrm{b}$ for breadth and $\mathrm{t}$ for thickness, including web ( $\mathrm{w}$ in subscript) and flange ( $f$ in subscript) thicknesses; in subscript, $C$ for column, $R$ for rafter and $\mathrm{H}$ for haunch.

FBC1 is defined as follows: $h_{c}, h_{R}=h_{H}, b_{C}=b_{R}=b_{H}, t_{w C}=t_{w R}=t_{w H}, t_{f C}=t_{f R}=t_{f H}$, and $H_{L}$. FBC1 also has 13 decision variables that are further constrained as shown in the equations.

FBC2 has the following properties: $h_{c}, h_{R}=h_{H}, b_{c}, b_{R}=b_{H}, t_{w c}, t_{w R}=t_{w H}, t_{f C}, t_{f R}=t_{f H}$, and $H_{L}$. Using restrictions for $\mathrm{FBC} 1$ and $\mathrm{FBC} 2$ corresponds to the operational simplicity and possibly economy of using a smaller numbers of plate sizes.

FBC3 has the following properties: $h_{c}, h_{R}, h_{H}, b_{c}, b_{R}, b_{H}, t_{w C}, t_{w R}, t_{w H}, t_{f C}, t_{f R}, t_{f H}$, and $H_{L}$.

In addition, discussions with manufacturers of fabricated beams suggest that the following geometric constraints are required in order to ensure that the plates can be welded and handled practically on the fabrication shop floor:

- $h_{C}>3 t_{f c} ; h_{R}>3 t_{f R} ; h_{H}>3 t_{f H}$

- $t_{f C}>t_{w C} ; t_{f R}>t_{w R} ; t_{f H}>t_{w H}$.

\section{Frame actions}

In this paper, the permanent actions $(\mathrm{G})$ and variable actions $(\mathrm{Q})$ assumed to act on the frames are as follows:

$$
\begin{aligned}
& \text { G: } \quad 0.55 \mathrm{kN} / \mathrm{m}^{2}+\text { self-weight of primary steel members } \\
& \text { Q: } \quad 0.60 \mathrm{kN} / \mathrm{m}^{2}
\end{aligned}
$$

Under vertical load, the frame should be verified at the ultimate and serviceability limit where the deflection limits and actions combination as recommended by the $\mathrm{SCl}[8,11]$ are adopted. Variable and permanent actions are factored in accordance with Eurocode 3: Design of steel structures [12]:

$$
\begin{aligned}
& \mathrm{ULS}=1.35 \mathrm{G}+1.5 \mathrm{Q} \\
& \mathrm{SLS} 1=1.0 \mathrm{G}+1.0 \mathrm{Q} \quad \text { (for absolute deflection) }
\end{aligned}
$$




$$
\mathrm{SLS} 2=1.0 \mathrm{Q} \quad \text { (for differential deflection relative to adjacent frame) }
$$

where,

ULS is the ultimate limit state

SLS is the serviceability limit state

\section{Ultimate limit state design}

\subsection{Elastic frame analysis}

Modern practice has shown that plastic design produces the most efficient designs in the majority of cases [2], [13]. Elastic design is still used, particularly when serviceability limit state deflections will control frame design [14], [15]. Phan et al. [8] have demonstrated that, if the $\mathrm{SCl}$ deflection limits are adopted, serviceability limit states control design. Therefore, elastic design is used in this paper.

A frame analysis program, written by the authors in MATLAB, was used for the purpose of the elastic frame analysis. The internal forces, namely, axial forces, shear forces, and bending moments can be calculated at any point within the frame. It should be noted that second-order effects are not considered, since the geometry in the benchmark frames satisfy the requirements for in-plane stability of the sway check method, described in BS $5950[16]$.

\subsection{Ultimate limit state design requirements}

Structural members are designed to satisfy the requirements for local capacity in accordance with Eurocode 3 [17]. Specifically, members are verified for capacity under shear, axial, and moment, and combined moment and axial force. For fabricated beams, the buckling curves used are taken in accordance with the UK National Annex [18]. Sections are classified based on the axial and bending force in conjunction with their geometric properties as class 1,2 or 3 . For class 1 or 2 sections, a plastic design approach is used in verification. For class 3 sections an elastic verification is substituted in the design. Sections outside this range (class 4 ) are excluded through use of a GA penalty. 
Local buckling verifications are excluded under the proviso that a more detailed design of any necessary web and flange stiffeners will be conducted on the optimum selected sections. For example the stiffeners are generally required in the eave connections to allow for the concentrated axial forces transference from the rafter to the column.

\subsubsection{Shear capacity}

The shear force, $V_{E d}$, should not be greater than the shear capacity, $V_{c, R d}$.

$$
\mathrm{V}_{\mathrm{Ed}} \leq \mathrm{V}_{c, \mathrm{Rd}}
$$

The shear capacity is given by:

$$
V_{c, R d}=\frac{A_{v}\left(f_{y} / \sqrt{3}\right)}{\gamma_{M 0}}
$$

where

$$
\begin{aligned}
& f_{y} \quad \text { is the yield stress of steel } \\
& A_{V} \quad \text { is the shear area } \\
& \gamma_{M 0} \quad \text { is partial factor for resistance } \\
& V_{c, R d} \quad \text { is the shear design resistance for class } 1,2 \text { and } 3 \text { sections }
\end{aligned}
$$

\subsubsection{Axial capacity}

The axial capacity should be verified to ensure that the axial force $\mathrm{N}_{\mathrm{Ed}}$ does not exceed the axial capacity $\left(\mathrm{N}_{\mathrm{Rd}}\right)$ of the member.

$$
\mathrm{N}_{\mathrm{Ed}} \leq \mathrm{N}_{\mathrm{c}, \mathrm{Rd}}
$$

\subsubsection{Moment capacity}

The bending moment should not be larger than the moment capacity of the cross section, $\mathrm{M}_{\mathrm{c}, \mathrm{Rd} \text {. }}$

$$
\mathrm{M}_{\mathrm{Ed}} \leq \mathrm{M}_{\mathrm{c}, \mathrm{Rd}}
$$

where

$M_{E d}$ is the moment applied to the critical section 
For class 1 or 2 sections $\mathrm{M}_{\mathrm{c}, \mathrm{Rd}}$ is the plastic design resistance of the section, $\mathrm{M}_{\mathrm{pl}, \mathrm{Rd}}$

For class 3 sections $\mathrm{M}_{c, \mathrm{Rd}}$ is the elastic design resistance of the section, $\mathrm{M}_{\mathrm{el}, \mathrm{Rd}}$

When members are subject to both compression and bending, the moment capacity $\mathrm{M}_{c, \mathrm{Rd}}$ is reduced if the axial force is significant in accordance with clause 6.2.9.1 for class 1 or 2 sections and check 6.2.9.2 for class 3 within Eurocode 3 Part 1-1 [17].

\subsubsection{Buckling}

Buckling is verified using equations 6.61 and 6.62 of Eurocode 3 [17]. As the frame is under single axis bending the additional second axis bending terms can be removed resulting in equation 5 and 6 below [19].

$$
\begin{aligned}
& \frac{N_{E d}}{N_{b, z, R d}}+k_{z y} \frac{M_{y, E d}}{M_{b, R d}}-1 \leq 0 \\
& \frac{N_{E d}}{N_{b, y, R d}}+k_{y y} \frac{M_{y, E d}}{M_{b, R d}}-1 \leq 0
\end{aligned}
$$

The equivalent uniform moment factors $k_{z y}$ and $k_{y y}$ interaction factors are calculated based on the Annex B method of Eurocode 3 [17]. Lateral restraint is provided by the side rails and purlins; torsional restraint is provided by the addition of stays to the bottom flange. Purlin and side rail spacing $\left(\mathrm{L}_{c r}\right)$ is generally controlled by the spanning capability of the cladding, normally 1 to $3 \mathrm{~m}$ depending on the loading. The rafter buckling is considered in zone $\mathrm{C}$ of Figure 1 and the column is verified equally at the column top (see Figure 2). In both cases a specified $L_{c r}$ restraint spacing is used in the calculation of stability based unity factors. In this paper feasible cladding spans of $1.5 \mathrm{~m}$ and $3 \mathrm{~m}$ are considered. Elsewhere in the frame where Lateral Torsional Buckling (LTB) is not explicitly considered it is assumed that restraints are provided at the necessary spacing to provide adequate stability.

\subsubsection{Shear Buckling}

The shear buckling check has been considered and was found not to control the design, based on unstiffened webs with non-rigid end posts verified, in accordance with EN-1993-15:2006 [20], with transverse stiffeners provided at the support and at the connections. The 
maximum observed reduction in shear force design capacity was $40 \%$, with an average reduction of $26.5 \%$ for the FC2 cases.

\section{Optimisation model}

The objective of the overall design optimisation is to determine the portal frame with the minimum primary member steel material weight, whilst satisfying the design requirements. The weight of the frame depends on the cross-section sizes of members. The objective function is expressed in terms of the weight of the primary members per square metre of the floor area. The weight was calculated by summation of the volume of steel material throughout the frame using element lengths and cross-sectional areas.

The design constraints unity factors are as follows:

$$
\begin{aligned}
& g_{1}=\frac{V_{E d}}{V_{c . R d}} \leq 1 \\
& g_{2}=\frac{N_{E d}}{N_{R d}} \leq 1 \\
& g_{3}=\frac{M_{E d}}{M_{c . R d}} \leq 1 \\
& g_{4}=\frac{N_{E d}}{N_{b, z, R d}}+k_{z y} \frac{M_{y, E d}}{M_{b, R d}} \leq 1 \\
& g_{5}=\frac{N_{E d}}{N_{b, y, R d}}+k_{y y} \frac{M_{y, E d}}{M_{b, R d}} \leq 1 \\
& g_{6}=\frac{\delta_{e} \leq 1}{\delta_{e}^{u}} \quad \text { if } 3 t_{\mathrm{f}}>h \\
& g_{7}=\frac{\delta_{a}}{\delta_{a}^{u}} \leq 1 \\
& 0 \text { therwise } \\
& \begin{array}{l}
1.2 \\
0
\end{array}
\end{aligned}
$$




$$
\begin{aligned}
& g_{9}=\left\{\begin{array}{cc}
1.2 & \text { if } \mathrm{t}_{\mathrm{w}}>\mathrm{t}_{\mathrm{f}} \\
0 & \text { Otherwise }
\end{array}\right. \\
& g_{10}=\left\{\begin{array}{cc}
1.2 & \text { if class } 4 \\
0 & \text { Otherwise }
\end{array}\right.
\end{aligned}
$$

where $\delta_{e}$ and $\delta_{a}=$ deflections at eaves and apex, respectively. The superscript $u$ indicates the maximum permissible deflection. The constraints for ultimate limit state design are $g_{1}$ to $g_{5}$ while the serviceability limit state design constraints are $g_{6}$ and $g_{7}$. Constraint $g_{1}$ is for shear capacity; $g_{2}$ is for axial capacity; $g_{3}$ is for combined axial and bending capacity; $g_{4}$ and $\mathrm{g}_{5}$ are interaction of axial force and bending moment on buckling for major axis; and $\mathrm{g}_{6}$ and $\mathrm{g}_{7}$ are for horizontal and vertical deflection limits. If the geometrical cross-section constraints, $g_{8}, g_{9}$ and $g_{10}$, is exceeded, an arbitrary (lowest tier) unity factor of 1.2 is assigned. These are verified throughout the frame and are further denoted to show the maximum value within a given zone: $g_{x c}$ within the column; $g_{x R}$ within the rafter; $g_{x H}$ within the haunch.

\section{Optimisation methodology}

The design optimisation considered in this paper contains mixed discrete and continuous design variables. This was implemented using a genetic algorithm within the optimisation toolbox in MATLAB. In order to consider discrete and continuous design variables, special crossover and mutation functions enforce variables to be integers [21]. One of the benefits of a real coded genetic algorithm is that genetic operators are directly applied to the design variables without coding and decoding as with binary string GAs. As demonstrated by Deb [22] real coded GA is appropriate for optimisation problems having continuous design variables. This allowed for the representation of the frame using realistic parameters that can be used directly in design.

It has been identified that genetic algorithms sometimes prematurely converge to a local optimum solution due to the domination of superior solutions in the current population [23], [24]. It has also been observed that using the real coded genetic algorithms, large population sizes are needed in order to obtain the optimum solution consistently [25]. 


\subsection{Genetic algorithm configuration}

Two techniques were explored in order to improve reliability and speed of convergence both applied prior to starting the GA. The first method is Search Space Reduction (SSR). Impressive reductions in GA execution times have been demonstrated recently. For example, Kadu et al. [26] used heuristics to limit the GA search to a region of the solution space in which near optimal solutions were thought to exist. Known constraint violations were used to maximise the proportion of feasible solutions even with geometric changes. This was done by initially calculating the frame bending moments using the maximum available sections then eliminating sections with significant lower moment capacities for both the column and rafter independently. This would reduce the number of sections considered from 80 to approximately 30 .

The second method is Improved Initial population (IIP) where the size of the initial population was larger than subsequent generations ensuring that several viable solutions were included in the first generation. The initial population was pre-generated using a Latin hypercube (LH) sampling plan. Two sizes of initial populations 6 and 12 times the standard GA population size were considered. The larger initial population was then ranked based on fitness value. The GA's second generation was then generated with a population created using 50\% from the larger initial population's best solutions and the rest randomly throughout the available search space by the GA.

The optimisation was conducted on a workstation (2.53 GHz CPU, 4GB RAM). Quoted computational times and function evaluation totals include the effort required in the phases before moving to the genetic algorithm. An outline of the GA stages is presented in Figure 3. Elite values are preserved 4 or 8 individuals, 4 for small populations and 8 for populations in excess of 150 individuals. Selection is conducted using roulette selection.

Mutation of the variables was performed using an adaptive feasible approach where mutation direction is based on the last successful or unsuccessful generation and the values are kept within the bounds of the optimisation. Selected parents are then combined using a scattered crossover operation where variables are converted to binary and the random bits from each are combined [27]. 
The optimisation was stopped when the maximum number of generations is reached, set at 100-250 generations. Additionally the optimisation was also terminated by convergence defined as 50 generations with no improvement; a function tolerance of $10^{-6}$ was specified. The maximum number of generations required generally was less than the maximum with almost all optimisations stops attributed to either the convergence criteria.

\subsection{Fitness and penalty functions}

The objective of the optimisation is the minimum weight of the primary members of the portal frame. This includes the weight of the column, rafter and haunch elements. For the haunch sections, this weight includes any wastage in material as a result of the fabrication. Figure 4 shows details of the cutting required for the section fabrication, with the white area representing wasted material, and $h_{H}$ the additional depth achieved once the section has been welded onto the rafter. The haunch sections are cut within the web outside the root radius, realistically reflecting fabrication cutting conditions.

To solve the optimisation problem, a penalty based approach was added to the calculated frame weight $\left(F_{\text {weight }}\right)$, see Equation 8 to obtain the optimisation fitness value $\left(F_{p}\right)$. Two levels of violation were considered, the standard violation penalty $(P)$ was a weight equivalent to the heaviest available configuration used to eliminate moderate violations (maximum constraint value under 1.5). For higher violations a penalty ten times the standard penalty value was added. The maximum value of any individual unity factor $\left(\mathrm{g}_{\mathrm{M}}\right)$ outlined in Section 5 was used to determine the extent of any violation. It was observed that high penalty values were required in order to eliminate very infeasible solutions. Otherwise the infeasible solutions would undercut feasible solutions.

$$
F_{p}= \begin{cases}F_{\text {weight }} & \text { if } g_{M} \leq 1 \\ F_{\text {weight }}+P & \text { if } 1<g_{M} \leq 1.5 \\ F_{\text {weight }}+10 P & \text { if } g_{M}>1.5\end{cases}
$$




\section{Results and discussion}

\subsection{Reliability study}

For different numbers of design variables (based on optimisation case) different global population sizes were investigated using a population based on a multiplier of 5, 10, 15, 20, 25 and 30 times the number of design variables with each optimisation run 30 times.

A total of 6 optimisation control strategies variations (see Table 1 and Table 2) were used, for 7 different sets of optimisation design variables consisting of 4 Universal Beam Cases (UBC) and 3 Fabricated Beam Cases (FBC). Table 1 includes the standard deviation, an indication of the reliability of the optimisation for different GA configurations. Table 2 shows the required number of function evaluations for a given configuration to achieve the reliability shown in Table 1 . This totalled 252 variations per frame considered each run 30 times. A representative result is presented in Table 1 and Table 2 for Frame A using UBC3. All of the optimisation cases (UBC1, UBC2...) produced comparable trends when switching between optimisation control strategies. It is observed that for both search space reduction and improved initial population, the standard deviation for small population multipliers is reduced significantly. As the computational effort required (in terms of mean function evaluations) increases, the standard deviation reduces to as low as $0.28 \mathrm{~kg} / \mathrm{m}^{2}$.

An example GA progress against function evaluations is shown in Figure 5 comparing the performance of the standard GA with the enhancement methods SSR and IIP. Achieving the global optimum for $\times 15$ multiplier is rare without SSR or IIP. However it would appear that local optimums are being found in the very near vicinity of the global optimum. From a designer's perspective, the additional effort required to achieve the global optimum, outweighs the time required to run the simulation. Using SSR only results in a faster convergence using less function evaluations due to a lower initial starting. Combining SSR with an IIP of 12 times the standard population results in the GA starting from an even lower starting fitness position but used more function evaluations. The increased number of function evaluations was only marginal, with lower fitness more consistently found; it is therefore useful for increasing reliability without disproportionately increasing optimisation time. Similar observations can be seen in Table 2 where more results are presented for comparison. 
The use of SSR allows for faster optimum convergence reducing function evaluations with the GA having a better starting position. IIP $(\times 12)$ has similar but less obvious benefits than simply increasing the global population multiplier. Increasing the global population multiplier significantly increases the number of function evaluations due to the stopping criteria in many cases being based on the number of stall generations. This will lead to higher numbers of individuals in each of the stall generations making it less efficient than using a combined SSR and IIP $(\times 12)$ approach which only has a large population in the first generation. It can also be seen IIP $(\times 12)$ also has a similar effect of SSR where the first generation will have a better starting position leading to a faster convergence.

\subsection{Recommended genetic algorithm configuration}

From reviewing the 30 run study a population multiplier of 15 seems to have an effective balance of reliability and computational effort. To further reduce the required computational effort it was necessary to decrease the number of GA iterations per optimisation run. As both reduction strategies allowed for lower optimum variation with reduced computational effort it is recommended that both search space reduction (where available) and an initial generation population multiplier of 12 is used (see bold numbers in Table 1 and Table 2). In order to check that the reliability was not unacceptably adversely affected a comparison is made between 10 and 30 runs (see Table 3 ).

The mean weight variation change from 30 GA runs to 10 runs is small indicating that 10 runs are sufficient for optimisation purposes. In general the optimum mean weight variation is below $2 \%$ of the optimum weight using 10 runs. The exception is FBC3, where a higher global population multiplier may be justified due to the larger number of interacting variables. The efficiency could be further improved by reducing the stall generation stopping constraint from 50 generations to 30 , eliminating unnecessary function evaluations. This was not implemented in this study as it would likely permit for faster convergence but with sacrificed reliability.

It is therefore recommended that this configuration is used for fast reliable results with all beam cases, with the exclusion of FBC3 where higher variations may be observed. It will be shown in Section 7.5 that case FBC3 is not recommended. Therefore optimising the GA configuration for FBC3 will not be explored further. 


\subsection{Comparison of results against previously reported in literature}

In order to validate the proposed modelling and optimisation method, a comparison is made against results previously published in the literature. It should be noted that all the examples in the literature are based on conventional hot-rolled steel portal frames. As each author calculated frame weight differently due to different geometric assumptions, a direct weight comparison is therefore not possible; instead the optimum chosen sections are compared.

In these comparisons it is assumed that the haunch would be fabricated i.e. the length and breadth of their haunch could be of any size. In practice the haunch is usually cut from a universal beam section (Figure 4) and this section is usually the same section as used for the rafter. The cut shown in Figure 4 is practical but the previous authors did not do this realistically. For the purposes of the comparisons described in this section, optimisation case UBC3 is considered; it should be noted that UBC1 and 2 produce similar weights.

\subsubsection{Issa and Mohammad}

The benchmark frame adopted by Issa \& Mohammad [6], as presented by Saka [5], is optimised. The frame considered is of span of $20 \mathrm{~m}$, height to eaves of $5 \mathrm{~m}$ and pitch of $8.53^{\circ}$. The load acting on the frame is $4 \mathrm{kN} / \mathrm{m}$ vertical UDL acting globally on the rafter.

Issa and Mohammad adopted deflection limits of $h_{f} / 300$ and $L_{f} / 360$ for the eaves and apex, respectively, which are more stringent than the $\mathrm{SCl}$ deflection limits. It should be noted that the deflection limits by Issa and Mohammad were verified at the same actions as the member verification, i.e. no distinction was made for the actions between ultimate limit state design and serviceability state for deflection verification. It should also be noted that although the optimisation conducted by Issa and Mohammad included member buckling effects, they reported in their paper that deflections limits governed this particular benchmark design; the frame is therefore suitable for use as a benchmark for comparison.

Table 4 shows the results of the optimisation. It can be seen that the section sizes for the column and rafter are the same as that of Phan et al. [8]. However, $H_{L}$ is longer than that of Phan et al., since the haunch is assumed to be cut from the same section as the rafter.

\subsubsection{SCI frame}


The benchmark frame adopted by Phan et al. [8], based on an $\mathrm{SCl}$ worked example [2], is also compared against the developed model. The frame geometry had a span of $30 \mathrm{~m}$, height to eaves of $7 \mathrm{~m}$ and pitch of $6^{\circ}$. The load acting on the frame is $11.3 \mathrm{kN} / \mathrm{m}$ vertical UDL, comprised of 0.66 and $0.6 \mathrm{kN} / \mathrm{m}^{2}$ for permanent and variable actions, respectively, with a frame spacing of $6 \mathrm{~m}$. For the comparison, the loading factors and constraints were altered to reflect the conditions reported. The $\mathrm{SCl}$ deflection limits were adopted.

The results of optimisation in comparison to Phan et al. are presented in Table 4. For UBC3 the same sections were selected as Phan et al. However, a longer $H_{L}$ was required. The cut haunch used in UBC3 is more realistic given it prevalence in the industry but is still comparable to Phan et al. results. The same primary members were selected under similar loading conditions and the total steel volumes within the haunches are similar.

\subsection{Portal frames composed of universal beams}

In this section, the optimisation benchmark frames described in Section 2 are optimised using the recommend GA configuration from Section 7.2. It should be noted that Frame $C$ span of $60 \mathrm{~m}$ was observed to be outside the range of UB based portal frames and therefore was only optimised using fabricated beams.

The results of the universal beam optimisation are presented in Table 5. As the number of design variables increase for both Frames $A$ and $B$, the primary structural weight reduces. In all cases, Eurocode capacity based moment verification dominates over others (shear and axial based). The deflection at the apex is binding. Using universal beam sections LTB was verified at both $1.5 \mathrm{~m}$ and $2.5 \mathrm{~m}$ restraint spacings $\left(L_{c r}\right)$. For Frames $A$ and $B, L T B$ was found not to be design controlling producing the same optimum results for both considered lengths.

The largest weight savings were found to be achieved by including the haunch section as a design variable within the GA. However, the sections selected tend to be significantly different than the rafter and column sections.

\subsection{Portal frames composed of fabricated beams}

Table 6 and Table 7 show the results of the portal frame optimisation composed of fabricated beams with restraint spacings $\left(L_{c r}\right)$ of $1.5 \mathrm{~m}$ and $2.5 \mathrm{~m}$, respectively. For ease of 
comparison, the dimensions of the fabricated beams are shown using the same designation as for standard universal beams i.e. depth $\times$ breadth $\times$ weight $($ in $\mathrm{kg} / \mathrm{m})$.

It can be observed that the dimensions of the fabricated beams are controlled by both deflections and buckling stability. In general the depth of the section is controlled by the deflection of the frame while the breadth controls the stability. Comparing Table 6 and Table 7, increasing the restraint spacing $\left(L_{c r}\right)$ from $1.5 \mathrm{~m}$ to $2.5 \mathrm{~m}$ results in an average optimum frame weight increase of $2.6 \%$. This increase in optimum frame weight is due to the additional steel needed to provide stability to the section.

The most proficient GA decision variable configuration was found to be $F B C 2$ where the haunch section is based on the rafter. When the haunch was allowed to vary independently from the rafter (FBC3) the haunch could be very shallow or significantly out of proportion with the rafter. This would produce the lightest frame weight but would make the fabrication and joint detailing very difficult. A much better option is a configuration where the haunch is based on the rafter (FBC2) resulting in a frame that can be fabricated more easily, with a minimal frame weight increase of $1-2 \%$ over the more optimum weight of FBC3.

\subsection{Observations}

In all cases, portal frames composed of fabricated beams are lighter than those using universal beams. Figure 6 compares the cross-section of Frame A with UBC3 and FBC2 drawn to scale side by side. It can be seen that the fabricated beams tend to be deeper generating the required moment capacity while sacrificing the inherent stability generally found in a rolled section by increasing the depth and reducing the breadth.

The change in sectional weight is presented in Figure 7 for Frames $A, B$ and $C$ for all optimisation cases (UBC1,UBC2...). Frame weights are separated into the component weights of the column, rafter and haunch. It can be seen going between optimisation cases that individual section weights do not always decrease. In some cases heavier column sections result in lighter frames overall. Additionally the weight contribution of the haunch is very small in comparison to the rest of the frame, making it an effective way of reducing deflections without adding unnecessary weight to the frame. 
If lateral restraint constraints are omitted for universal beams frames in the vast majority of cases the optimum configuration will not change. This is due to the inherent stability generated from their flanges this is significantly different for the fabricated beams. Without the need for stability the optimum shape for cross-sectional area is a thin rectangle due to the more efficient generation of second moment of area. This is also true for both elastic and plastic modulus resulting in very unstable unfeasibly thin rectangular sections. The inclusion of lateral restraint is therefore essential in the design of fabricated beams, controlling to an extent breadth and thickness of the flanges.

If serviceability limits are omitted, significantly lighter structures can be obtained, see Table 8, in comparison to Tables 5-7. When serviceability is ignored the controlling factor for universal beams reverts to bending moment unity factors. This results in the selection of sections based on plastic section modulus. However, the building deflection under differential loading would result in cladding damage and water ingress. For fabricated beams it becomes a combination of both bending and stability.

\section{Building topography parametric study}

In the previous section, it was shown that fabricated beam sections produce lighter frame weights. This section investigates this saving across the range of standard portal frame sizes. Spans considered in the study range from $14 \mathrm{~m}$ to $50 \mathrm{~m}$; column heights range from $4 \mathrm{~m}$ to $12 \mathrm{~m}$. The pitch and frame spacing for all frames are $10^{\circ}$ and $6 \mathrm{~m}$, respectively, resulting in a grid of $19 \times 9$ data points (highlighted in the contour plots by a dot).

The optimum designs for the frames in this section are obtained by running 10 optimisations per case using $\mathrm{UBC} 3$ and $\mathrm{FBC2}$. UBC3 and FBC2 are chosen in the parametric study to allow the maximum number of design variables while avoiding impractical haunch configuration. For UBC3 each optimisation required on average 2906 function calls ( 53 generations +540 initial population). Running each point ten times required 42 minutes of computational time. FBC2 on average required 10095 function calls (60 generations +2025 initial population) requiring 10 runs approximately 2 hours and 20 minutes of computational time. The increases in optimisation time $(\approx \times 3.5)$ moving from beam based to plate based is 
noticeable but still quick enough that it could be used within the design environment making the additional weight saving achievable.

For each case, the minimum weight was obtained (in terms of $\mathrm{kg} / \mathrm{m}^{2}$ ).

Figure 8 a shows the contours of minimum weight of frames with a restraint spacing of $1.5 \mathrm{~m}$ using universal beams. A monotonic trend is seen, of increasing frame weight with both span and column height.

This study has a number of improvements over the similar universal beam optimisation presented by Phan et al. [8]. In the previous study the frame self-weight remained constant with a lower permanent actions. It was found that self-weight significantly increased the weight of the frames particularly in long span frames accounting for in excess of half the permanent frame loading. This study therefore more accurately reflects the weight of portal frames with the range of geometric configurations presented.

Figure $8 \mathrm{~b}$ shows equivalent weights using fabricated beams again with $1.5 \mathrm{~m}$ restraint spacing; the span column height trend continues, but the weights are consistently lower. Figure 9 shows the percentage reduction in weight using fabricated beams. Both fabricated and rolled optimal solutions do not include the weight of the connections and stiffeners, which for fabricated beams may be higher. For short span and column height frames the weight savings are minimal $(<5 \%)$. For long span and column height frames the savings can be significant. For frame spans in excess of $30 \mathrm{~m}$, weight savings of $14 \%$ in primary members can be expected (up to $19 \%$ in some instances). The savings are not consistent from case to case due to the variation in optimality of different beam cases. However, there is a strong trend in that the longer the span the higher the potential savings. It should be noted that without fabrication constraints, savings of up $30 \%$ are achievable. However this requires the web to be thicker than the flange which is inconsistent with fabrication practices and limitations.

The universal beam based frames are much less susceptible to the influence of stability. Figure 10a shows the growth in frame weight when increasing the restraint spacing from 1.5 $\mathrm{m}$ to $3.5 \mathrm{~m}$. Frame weight changes occur in only short span buildings under $25 \mathrm{~m}$ with a maximum weight increase of $15 \%$ for the shortest span frames. 
There is considerably more variation in the fabricated beams. Figure $10 \mathrm{~b}$ and Figure $10 \mathrm{c}$ show the weight difference for a restraint spacing increased from $1.5 \mathrm{~m}$ to 2.5 and $3.5 \mathrm{~m}$, respectively. For a $1 \mathrm{~m}$ increase, there is a weight increase of $0-12 \%$ and for $2 \mathrm{~m}$, a weight increase of $0-16 \%$. The largest increases are for small span frames. This can be explained by the limited available plate thicknesses.

Larger span frames have significantly lower weight increases of approximately $2 \%$ and $4 \%$ for $1 \mathrm{~m}$ and $2 \mathrm{~m}$, respectively. This can be attributed to the ability of the GA to redistribute steel within the cross-section towards the required attributes. As steel within the flanges not only provides stability but also adds moment capacity and stiffness allowing for crosssectional area migration from the web to the flange as needed.

\section{Conclusions}

Fabricated beam portal frames have a distinct weight advantage over universal beam based frames with an achievable weight saving of $15 \%$ in primary frame weight for large span frames (>40 m). Fabricated beams in portal frames are controlled by two governing constraints: the buckling stability of the sections, and serviceability limits of the frame (deflection).

For medium to long span frames, universal beam optimised frame sections are governed by serviceability, with the exception of small span frames which are more susceptible to buckling constraints that should be included in the optimisation when using universal beam based frames.

The geometric cross-sectional dimensional constraints placed on the optimisation have a significant influence on the weight obtained. Where an insufficient range of plate thicknesses is provided, the fabricated section will have weight comparable, or in excess of a rolled based design. If the flange and web thicknesses are allowed to vary independently of each other the fabricated beam weight savings are increased significantly by an additional $10-15 \%$. The choices of optimisation design variables are important. FBC3 although consistently the lightest solution would generate less than ideal haunch configurations where the geometry would have insufficient depth for bolts or have excessively long shallow flanges. It is recommended to have a configuration similar to FBC2 where the haunch 
section was based on the rafter, or have more complex haunch based geometric constraints in place. Universal beam based frames were found to have similar issues when the haunch was allowed to fully vary (UBC4) with a similar recommendation to base the haunch on the rafter (UBC3).

Using plate lines and automated fabrication will be more expensive than readily available stocked rolled sections for small frames. However, in large long span projects, the $15 \%$ weight saving may make it an economically attractive viable solution. Fabricated beams will be ill-advised for small frames where savings are minimal. However, for larger frames or frames outside the range of universal beams $(50+m)$ they provide a lighter solution.

A genetic algorithm with a population 15 times the number of variables with a larger initial population and reduced search space, was capable of producing reliable repeatable results in an industry acceptable time frame for both fabricated and universal beam based frames. Fabricated beams require approximately 3.5 times longer than universal beam based optimisations but are still viable for design completing in less than 3 hours. This would allow for the comfortable automated optimisation of multiple frames outside normal working hours overnight within the industry. Further work would be to examine tapered beams and the inclusion of local buckling section verifications.

\section{Acknowledgements}

The financial support from the Queen's University Belfast is gratefully acknowledged.

\section{References}

[1] Davison B, Owens G. eds., Steel designers' manual, 6th edition. Blackwell Publishing; 2008.

[2] Salter PR, Malik AS, King CM. Design of single-span steel portal frames to BS 5950-1: 2000. SCI publication P252. Ascot: The Steel Construction Institute; 2004.

[3] Chen Y, Hu K. Optimal design of steel portal frames based on genetic algorithms. Front Archit Civ Eng China 2008;2(4):318-22. 
[4] Leinster JC, Rankin GIB, Robinson DJ. Novel loading tests on full-scale tapered member portal frames. Proc ICE - Struct Build 2009;162(3):151-59.

[5] Saka MP. Optimum design of pitched roof steel frames with haunched rafters by genetic algorithm. Comput Struct 2003;81:1967-78.

[6] Issa HK, Mohammad FA. Effect of mutation schemes on convergence to optimum design of steel frames. J Constr Steel Res 2010;66(7):954-61.

[7] Kravanja S, Turkalj G, Šilih S, Žula T. Optimal design of single-story steel building structures based on parametric MINLP optimization. J Constr Steel Res 2013;81:86103.

[8] Phan DT, Lim JBP, Tanyimboh TT, Lawson RM, Xu Y, Martin S, Sha W. Effect of serviceability limits on optimal design of steel portal frames. J Constr Steel Res 2013;86:74-84.

[9] British Standards. BS EN 10025-2: Hot rolled products of structural steels. Technical delivery conditions for non-alloy structural steels. London: British Standards Institution; 2004.

[10] Tata Steel. Steel building design: Design data, in accordance with Eurocodes and the UK national annexes. 2013.

[11] Advisory Desk SCI. AD-090: deflection limits for pitched roof portal frames (Amended). Ascot: The Steel Construction Institute; 2010.

[12] British Standards. Eurocode 3: Design of steel structures, vol. 3, no. 1. London: British Standards Institution; 2002.

[13] Davies JM, Brown BA. Plastic design to 5950. Ascot: The Steel Construction Institute; 1996.

[14] Lim JBP, Nethercot DA. Serviceability design of a cold-formed steel portal frame having semi-rigid joints. Steel Compos Struct 2003;3(6):451-74.

[15] Lim JBP, Nethercot DA. Finite element idealization of a cold-formed steel portal frame. J Struct Eng, ASCE 2004;130(1):78-94. 
[16] British Standards. BS 5950: Structural use of steelworks in building. Part 1. Code of practice for design-rolled andwelded sections. London: British Standards Institution; 2001.

[17] British Standards. BS EN 1993-1-1: Eurocode 3: Design of Steel Structures. Part 1-1. General rules and rules for buildings. London: British Standards Institution; 2005.

[18] British Standards. NA to BS EN 1993-1-1: UK National Annex to Eurocode 3: Design of steel structures. London: British Standards Institution; 2005.

[19] Koschmidder DM, Brown DG. Elastic design of single-span steel portal frame buildings to Eurocode 3. SCI publication P397. Ascot: The Steel Construction Institute; 2012.

[20] British Standards. BS EN 1993-1-5: Eurocode 3 - Design of steel structures - Part 15: Plated structural elements. London: British Standards Institution; 2006.

[21] Deep K, Singh KP, Kansal ML, Mohan C. A real coded genetic algorithm for solving integer and mixed integer optimization problems. Appl Math Comput 2009;212(2):505-18.

[22] Deb K. An efficient constraint handling method for genetic algorithms. Comput Methods Appl Mech Eng 2000;186:311-38.

[23] Deb K. Multi-objective optimization using evolutionary algorithms. John Wiley and Sons, Inc.: Chichester; 2001, p. 518.

[24] Deb K, Gulati S. Design of truss-structures for minimum weight using genetic algorithms. Finite Elem Anal Des 2001;37:447-65.

[25] Phan DT, Lim JBP, Sha W, Siew C, Tanyimboh T, Issa H, et al. Design optimization of cold-formed steel portal frames taking into account the effect of topography. Eng Optim 2013;45:415-33.

[26] Kadu MS, Gupta R, Bhave PR. Optimal design of water networks using a modified genetic algorithm with reduction in search space. J Water Resour Plan Manag 2008;134(2):147-60. 
[27] Mathworks. Global optimization toolbox user's guide R 2013b. The MathWorks, Inc; 2013. 


\section{Figures}

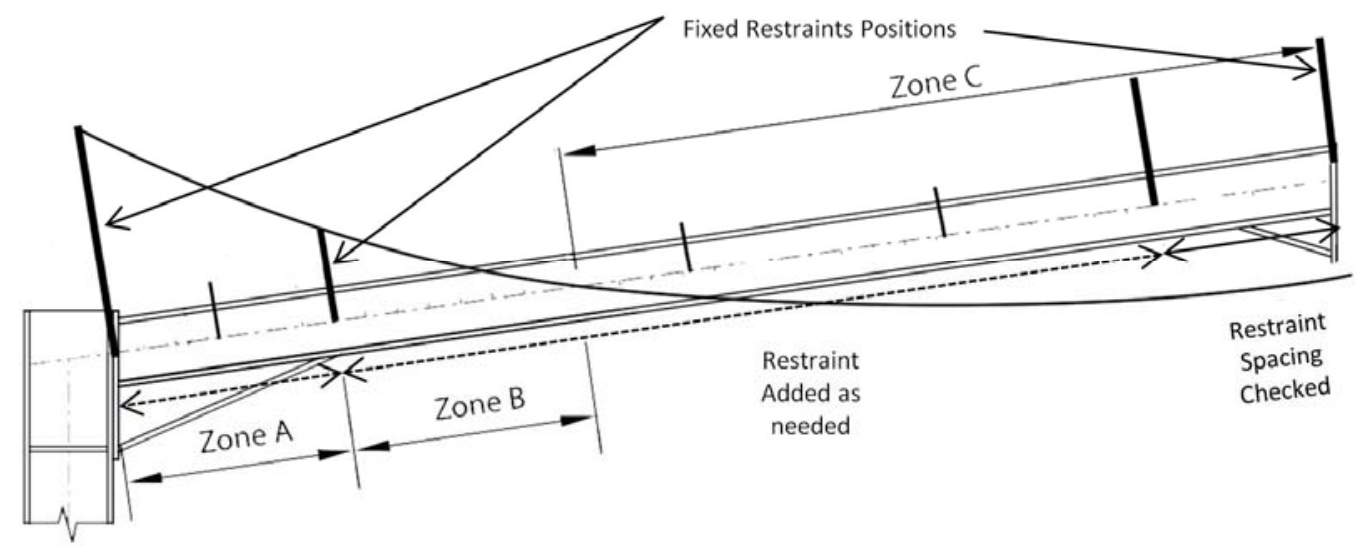

Figure 1 Buckling zones of rafter after [19]

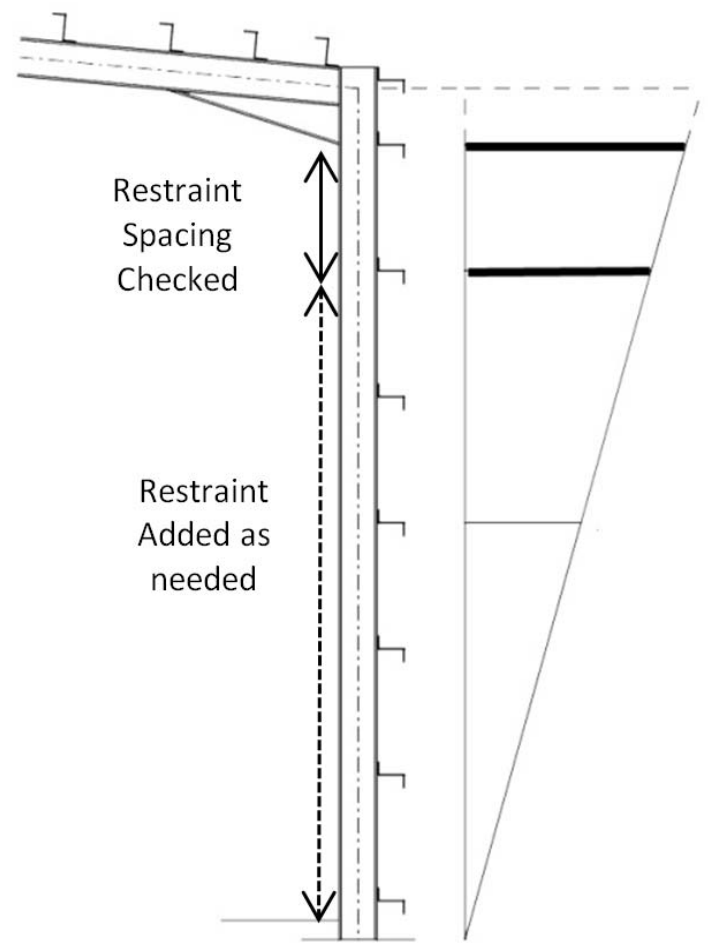

Figure 2 Critical buckling restraint positions of column after [19] 


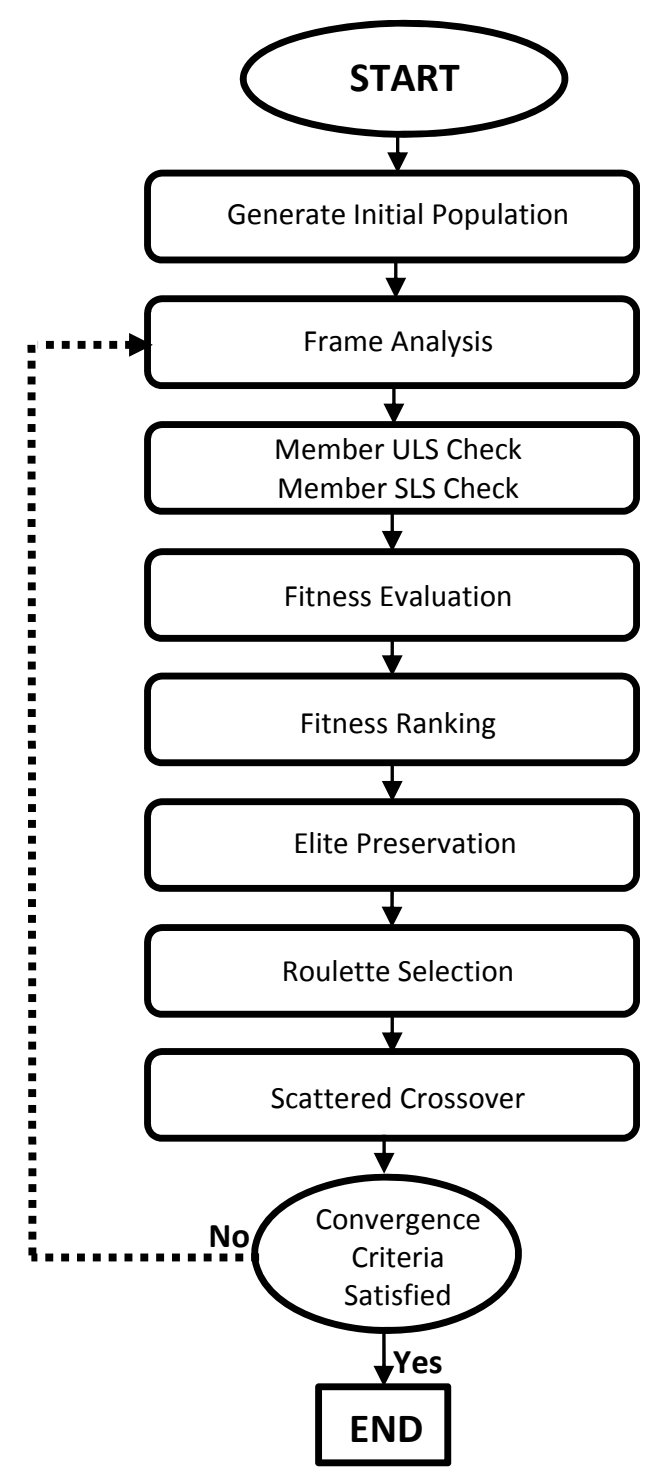

Figure 3 Flowchart of genetic algorithm
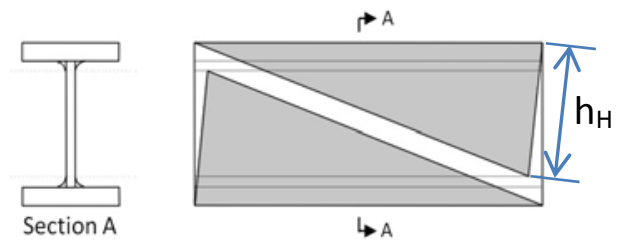

Figure 4 Details of eaves haunch cut from universal beam section. The white area in the figure on the right-hand side is wastage 


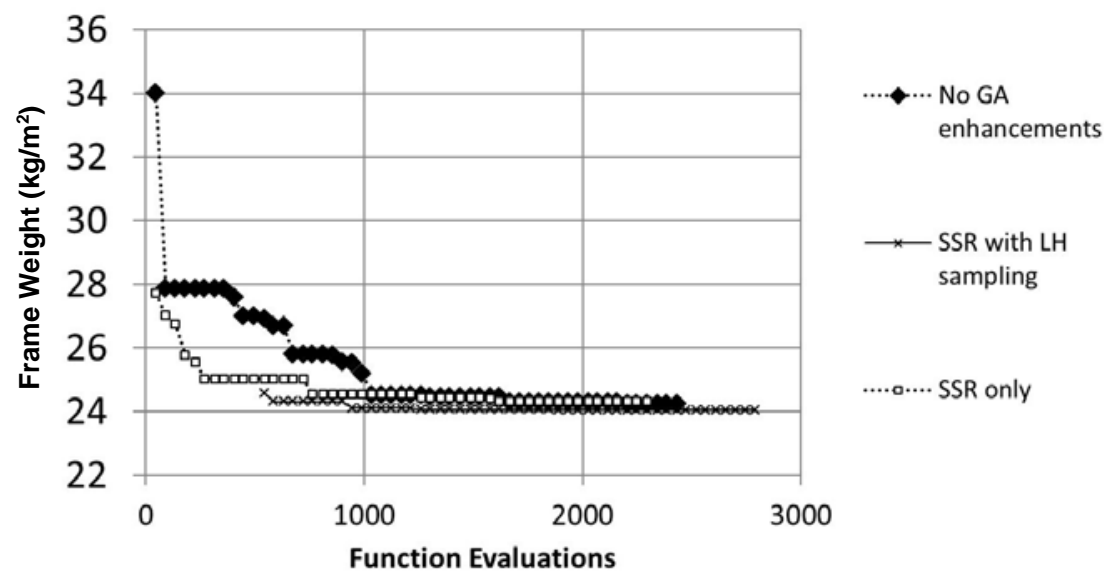

Figure 5 Convergence history for different genetic algorithm strategies

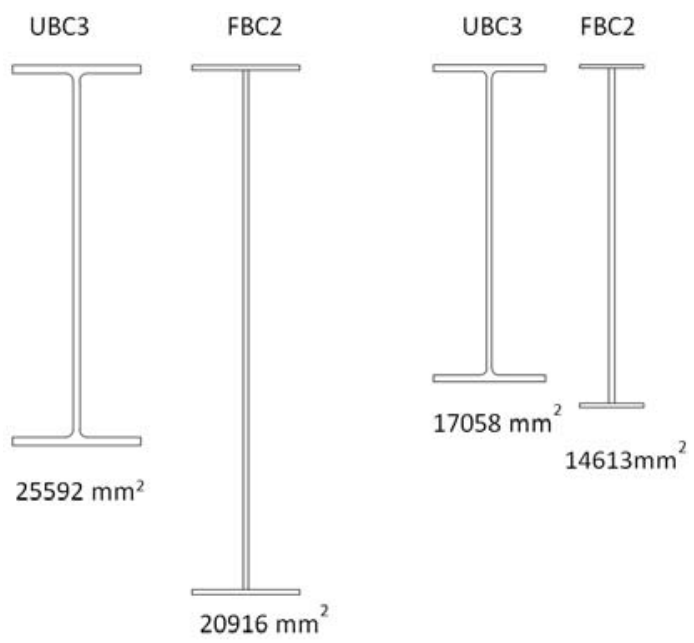
(a) Column
(b) Rafter

Figure 6 Comparison of optimum cross-sections for Frame A using UBC3 and FBC2 


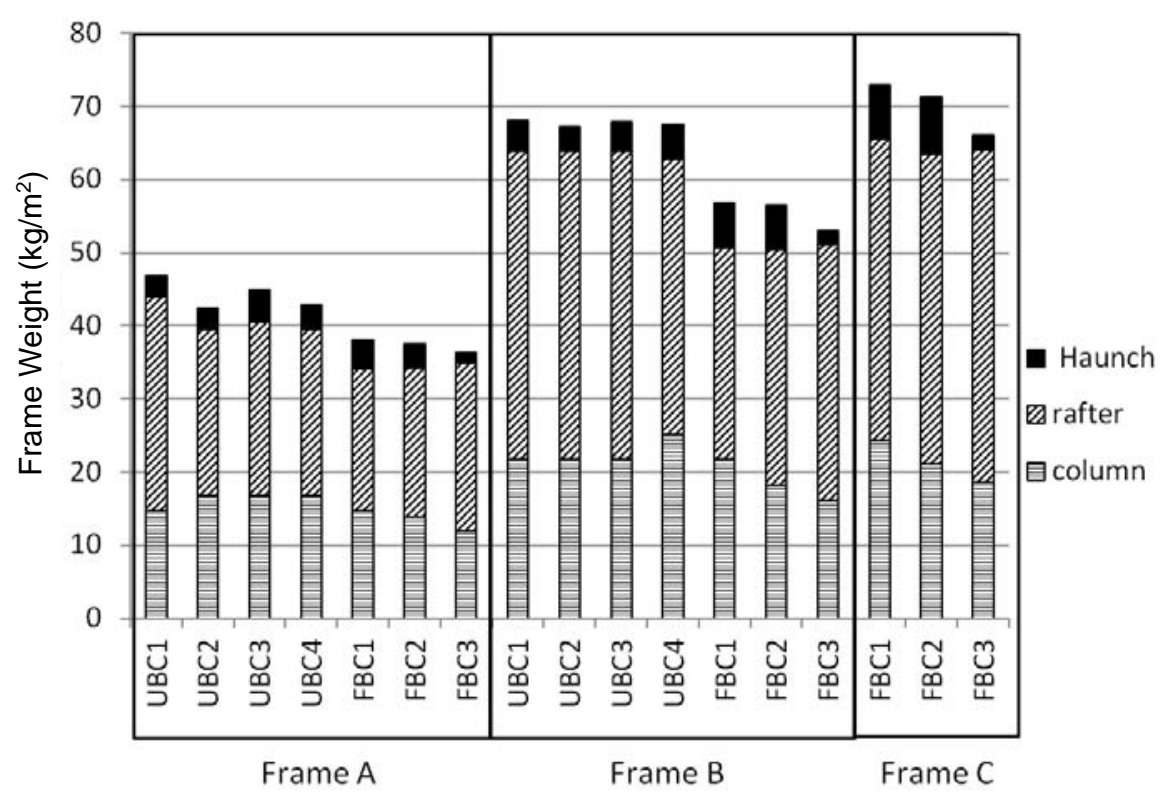

Figure 7 Optimum frame weight for $L_{c r}=1.5 \mathrm{~m}$ 


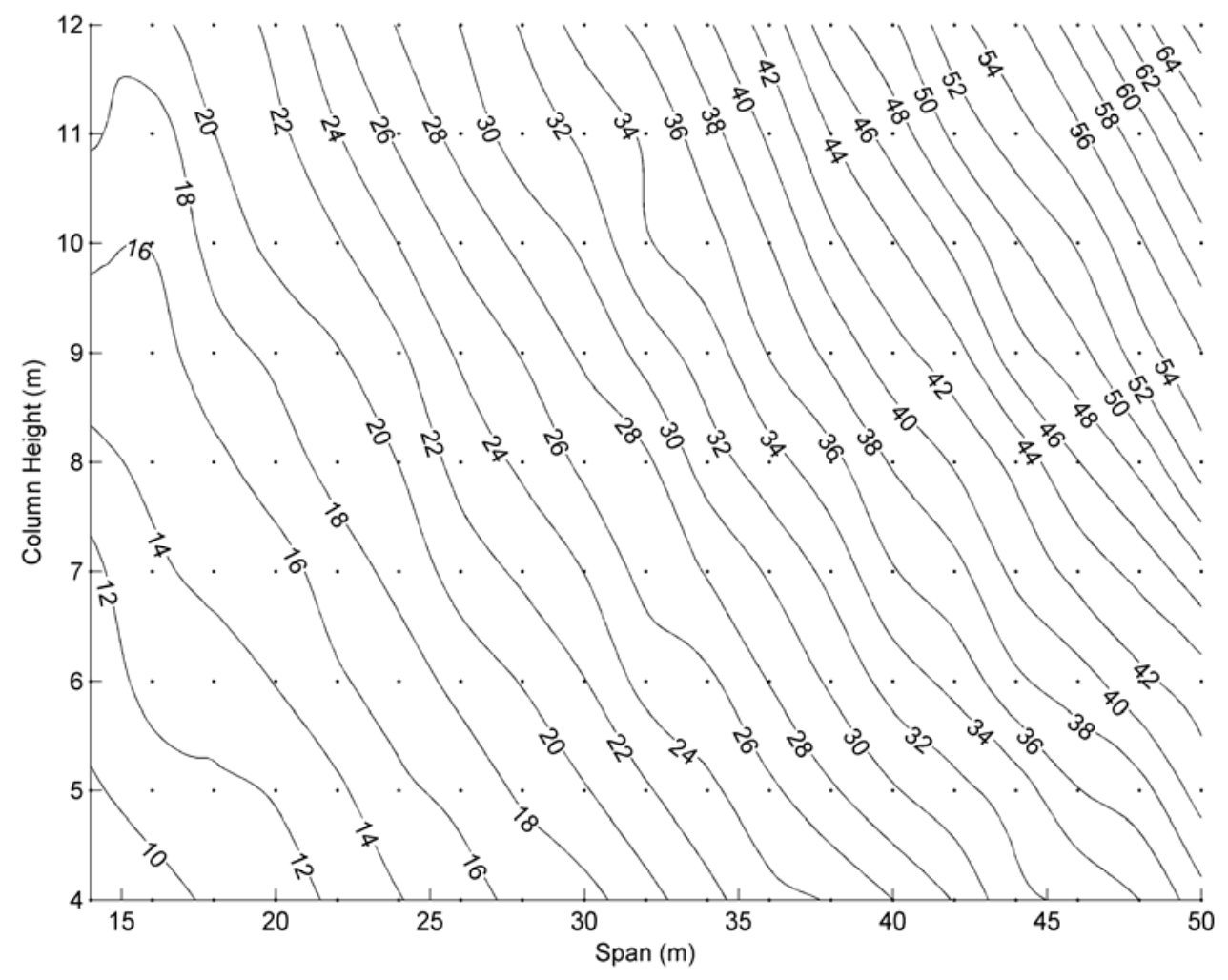

(a) UBC3

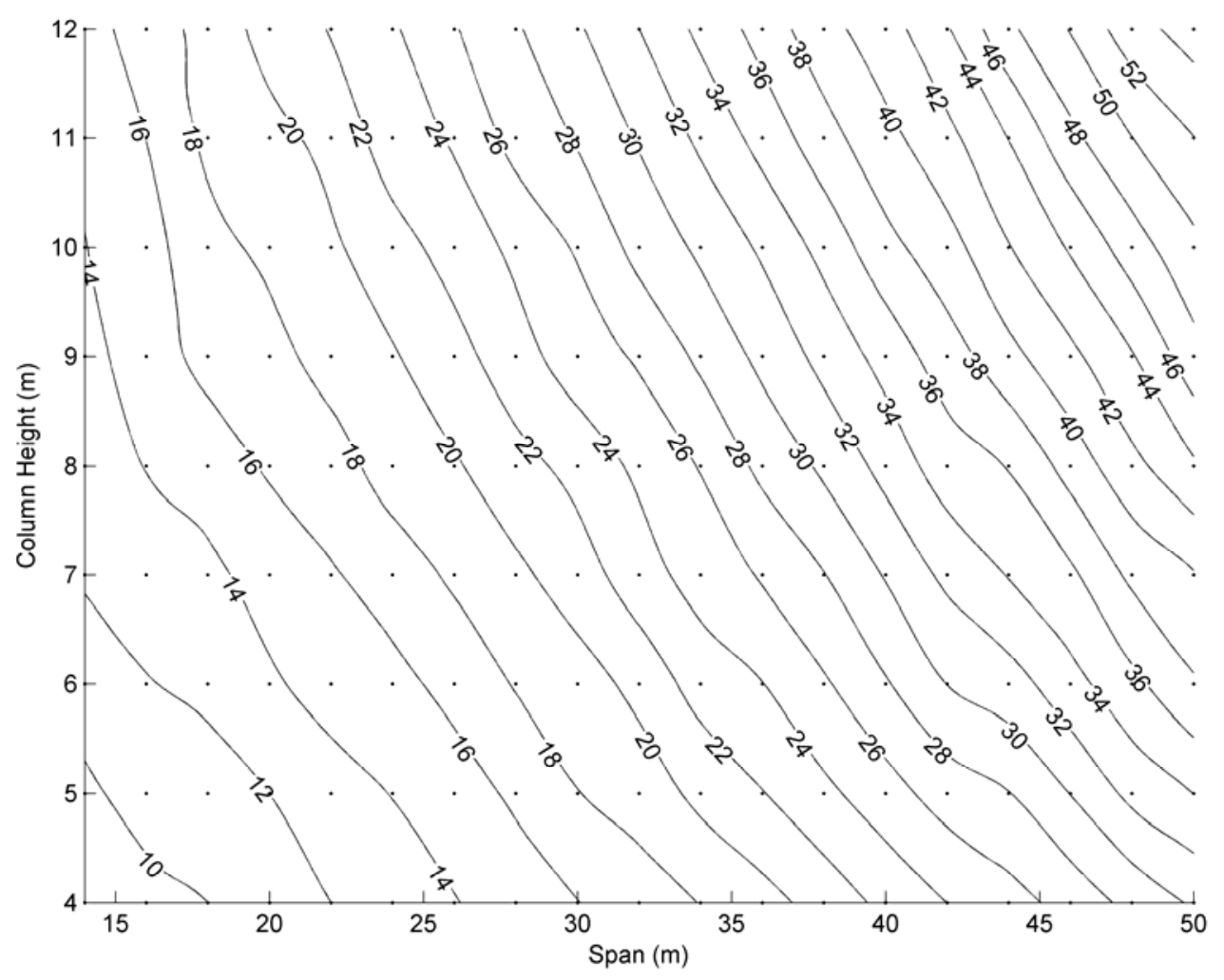

(b) $\mathrm{FBC2}$

Figure 8 Contour of frame weight $\left(\mathrm{kg} / \mathrm{m}^{2}\right)$ for (a) UBC3 and (b) FBC2 with $\mathrm{L}_{\mathrm{cr}}=1.5 \mathrm{~m}$ 


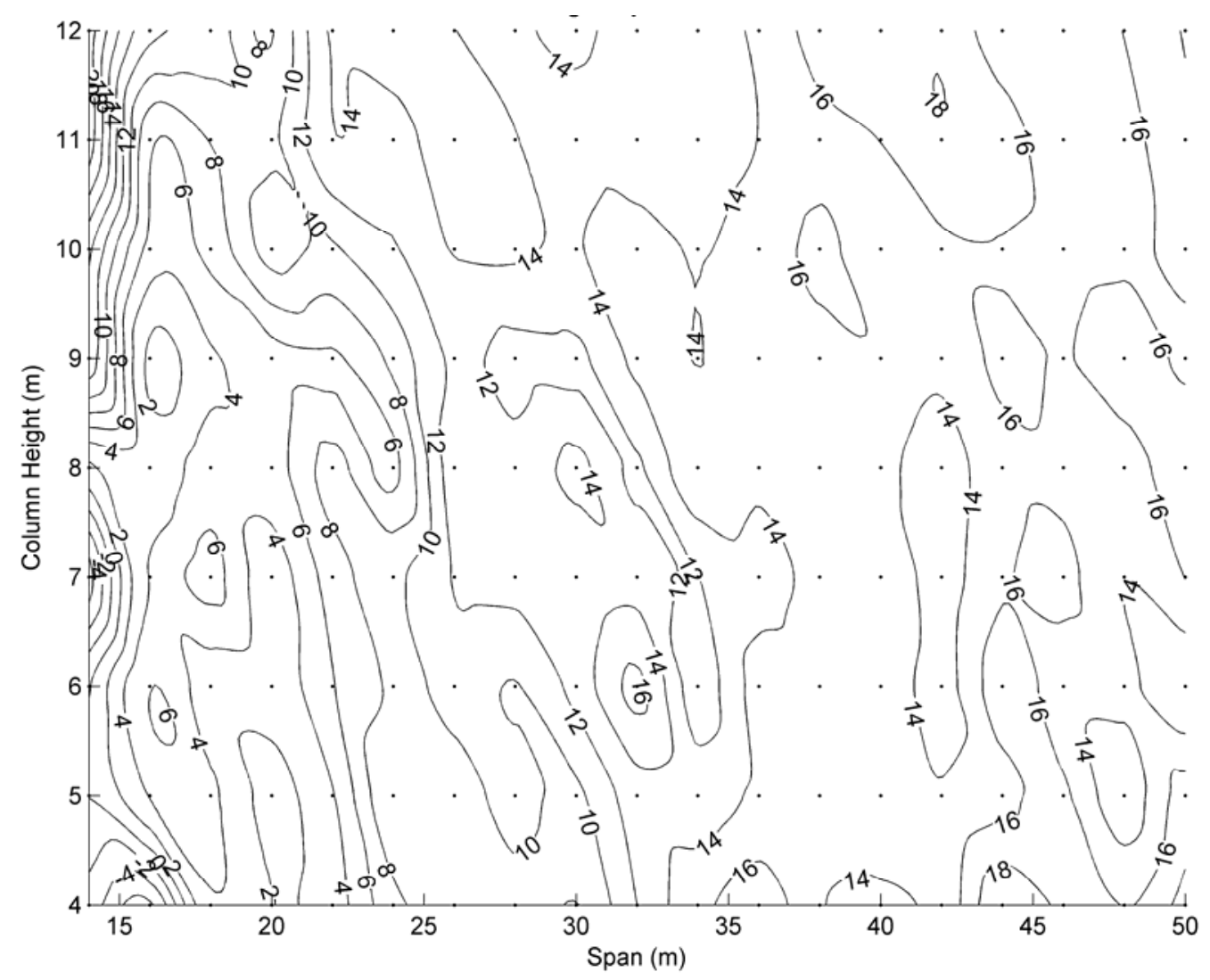

Figure 9 Contour of percentage saving in frame weight of $F B C 2 / U B C 3$ with $L_{c r}=1.5 \mathrm{~m}$ 


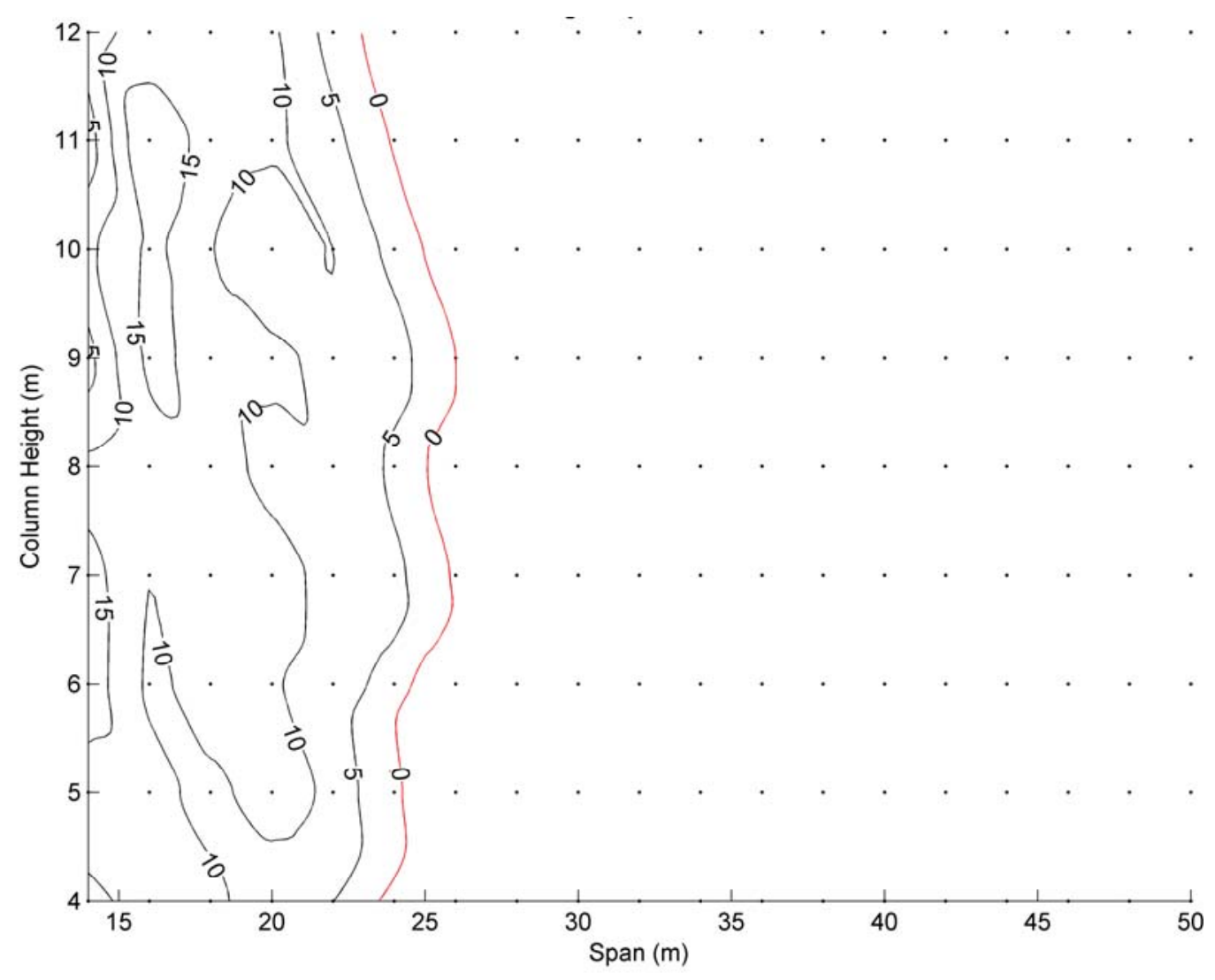

(a)

Figure 10 Contour of percentage increase in frame weight for (a) UBC3 when increasing $L_{c r}$ from $1.5 \mathrm{~m}$ to $3.5 \mathrm{~m}$, and $\mathrm{FBC} 2$ when increasing $\mathrm{L}_{\mathrm{cr}}$ from $1.5 \mathrm{~m}$ to (b) $2.5 \mathrm{~m}$ and (c) $3.5 \mathrm{~m}$ 


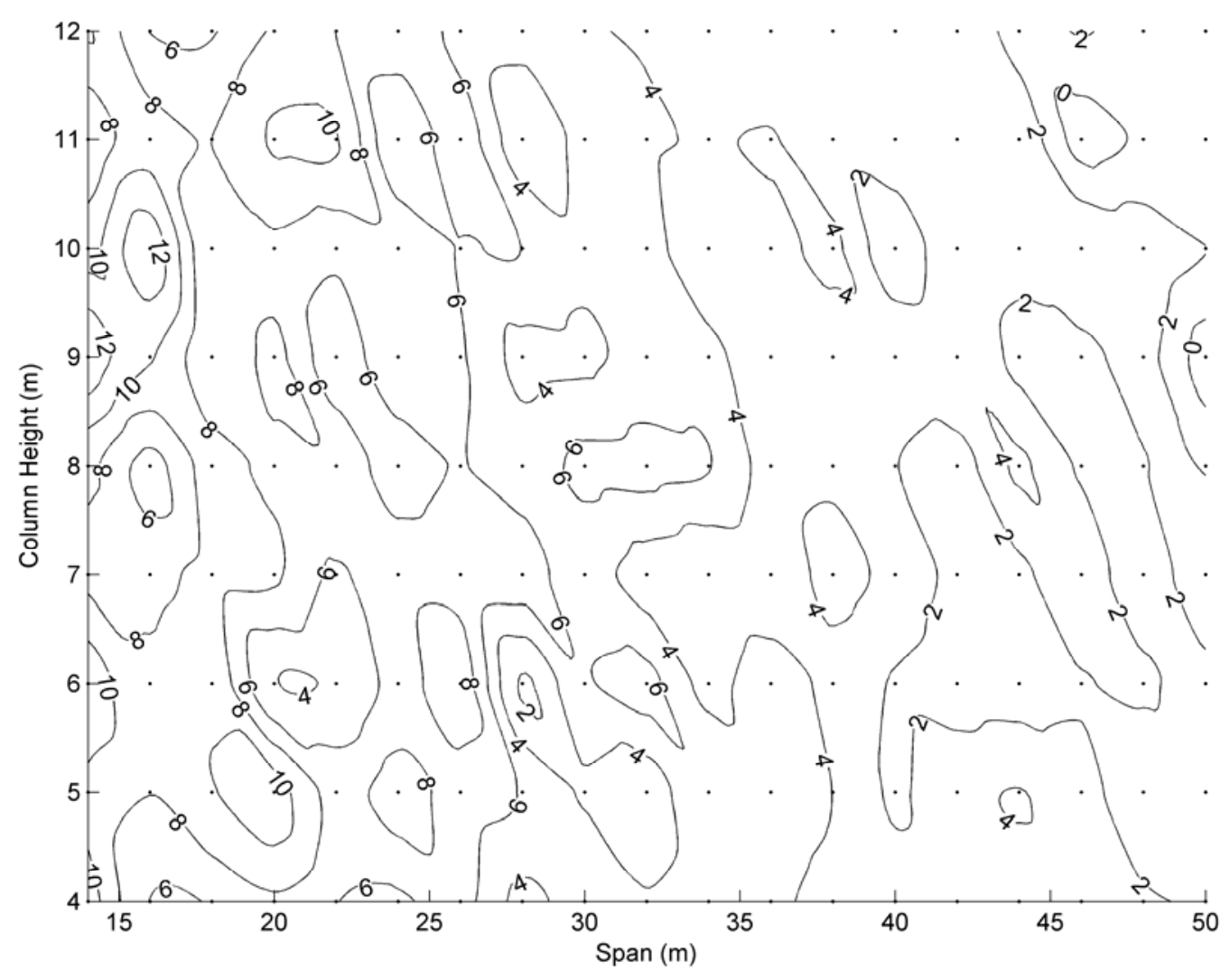

(b)

Figure 10 Contour of percentage increase in frame weight for (a) UBC3 when increasing $L_{c r}$ from $1.5 \mathrm{~m}$ to $3.5 \mathrm{~m}$, and $\mathrm{FBC} 2$ when increasing $L_{c r}$ from $1.5 \mathrm{~m}$ to (b) $2.5 \mathrm{~m}$ and (c) $3.5 \mathrm{~m}$ 


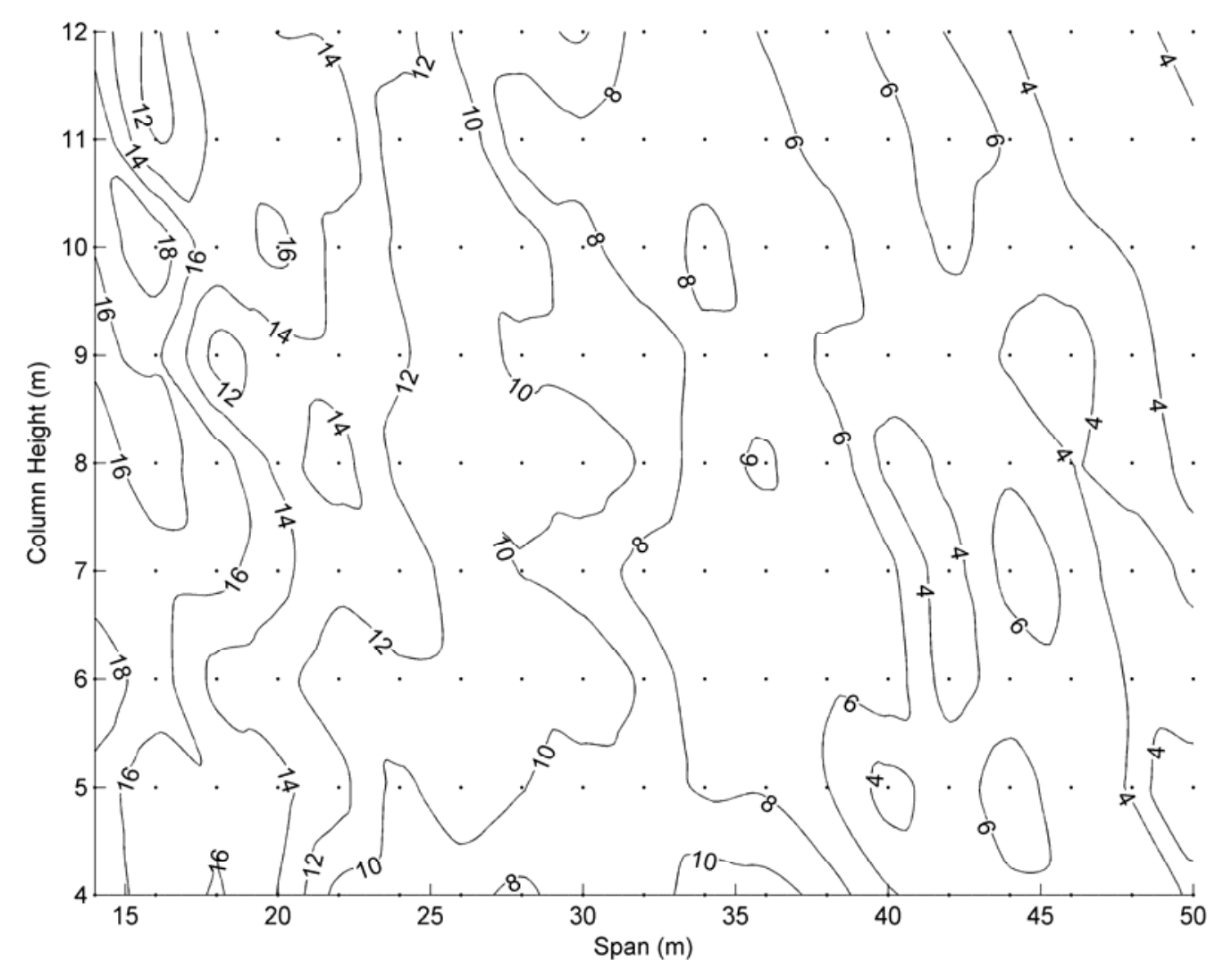

(c)

Figure 10 Contour of percentage increase in frame weight for (a) UBC3 when increasing $L_{c r}$ from $1.5 \mathrm{~m}$ to $3.5 \mathrm{~m}$, and $\mathrm{FBC} 2$ when increasing $L_{c r}$ from $1.5 \mathrm{~m}$ to (b) $2.5 \mathrm{~m}$ and (c) $3.5 \mathrm{~m}$ 


\section{Tables}

Table 1 Reliability of genetic algorithm for Frame A using UBC3

\begin{tabular}{|c|c|c|c|c|c|c|c|}
\hline \multirow{2}{*}{\multicolumn{2}{|c|}{ Optimisation strategy }} & \multicolumn{6}{|c|}{ GA population multiplier } \\
\hline & & 5 & 10 & 15 & 20 & 25 & 30 \\
\hline $\begin{array}{l}\text { Initial } \\
\text { Population } \\
\text { (IP) }\end{array}$ & $\begin{array}{l}\text { Search Space } \\
\text { Reduction } \\
\text { (SSR) } \\
\end{array}$ & \multicolumn{6}{|c|}{$\begin{array}{c}\text { Mean weight (kg per m²) } \\
\text { (Standard deviation) }\end{array}$} \\
\hline Normal & None & $\begin{array}{l}47.82 \\
(6.44)\end{array}$ & $\begin{array}{l}44.44 \\
(1.84)\end{array}$ & $\begin{array}{l}43.87 \\
(1.10)\end{array}$ & $\begin{array}{l}43.31 \\
(0.71)\end{array}$ & $\begin{array}{l}43.28 \\
(0.49)\end{array}$ & $\begin{array}{l}43.27 \\
(0.68)\end{array}$ \\
\hline ×6 Larger & None & $\begin{array}{l}47.76 \\
(6.27)\end{array}$ & $\begin{array}{l}43.73 \\
(1.20)\end{array}$ & $\begin{array}{l}43.34 \\
(0.49)\end{array}$ & $\begin{array}{l}43.21 \\
(0.65)\end{array}$ & $\begin{array}{l}43.07 \\
(0.63)\end{array}$ & $\begin{array}{l}43.23 \\
(0.65)\end{array}$ \\
\hline$\times 12$ Larger & None & $\begin{array}{l}46.05 \\
(1.76)\end{array}$ & $\begin{array}{l}44.58 \\
(1.09)\end{array}$ & $\begin{array}{l}44.53 \\
(0.83) \\
\end{array}$ & $\begin{array}{l}44.27 \\
(0.44)\end{array}$ & $\begin{array}{l}44.39 \\
(0.63)\end{array}$ & $\begin{array}{l}44.43 \\
(0.51)\end{array}$ \\
\hline Normal & Yes & $\begin{array}{l}45.21 \\
(1.91)\end{array}$ & $\begin{array}{l}43.53 \\
(0.88) \\
\end{array}$ & $\begin{array}{l}42.97 \\
(0.50)\end{array}$ & $\begin{array}{l}43.00 \\
(0.52)\end{array}$ & $\begin{array}{l}42.89 \\
(0.50)\end{array}$ & $\begin{array}{l}42.89 \\
(0.48) \\
\end{array}$ \\
\hline$\times 6$ Larger & Yes & $\begin{array}{l}44.39 \\
(1.45)\end{array}$ & $\begin{array}{l}43.28 \\
(0.65)\end{array}$ & $\begin{array}{l}43.12 \\
(0.49)\end{array}$ & $\begin{array}{l}42.89 \\
(0.44)\end{array}$ & $\begin{array}{l}42.86 \\
(0.43)\end{array}$ & $\begin{array}{l}42.85 \\
(0.45)\end{array}$ \\
\hline$\times 12$ Larger & Yes & $\begin{array}{l}45.00 \\
(1.00)\end{array}$ & $\begin{array}{l}44.28 \\
(0.82)\end{array}$ & $\begin{array}{l}44.07 \\
(0.47)\end{array}$ & $\begin{array}{l}44.06 \\
(0.43)\end{array}$ & $\begin{array}{l}43.97 \\
(0.27)\end{array}$ & $\begin{array}{l}43.99 \\
(0.28)\end{array}$ \\
\hline
\end{tabular}

Table 2 Average number of function evolutions for Frame A using UBC3

\begin{tabular}{|l|l|l|c|c|c|c|c|}
\hline \multirow{2}{*}{\begin{tabular}{l} 
Optimisation strategy \\
\cline { 3 - 8 }
\end{tabular}} & \multicolumn{7}{|c|}{ GA population multiplier } \\
\cline { 2 - 8 } $\begin{array}{l}\text { Initial } \\
\begin{array}{l}\text { Population } \\
\text { (IP) }\end{array}\end{array}$ & $\begin{array}{l}\text { Search Space } \\
\text { Reduction } \\
\text { (SSR) }\end{array}$ & \multicolumn{6}{|c|}{ Average number of function evaluations } \\
\hline Normal & None & 815 & 1645 & 2490 & 3261 & 3996 & 4876 \\
\hline$\times 6$ Larger & None & 885 & 1778 & 2728 & 3485 & 4471 & 5539 \\
\hline$\times 12$ Larger & None & 984 & 1975 & 2985 & 3961 & 4939 & 5869 \\
\hline Normal & Yes & 783 & 1592 & 2379 & 3129 & 3954 & 4747 \\
\hline$\times 6$ Larger & Yes & 884 & 1755 & 2647 & 3513 & 4376 & 5266 \\
\hline$\times 12$ Larger & Yes & 1000 & 1968 & 2959 & 3871 & 4851 & 5923 \\
\hline
\end{tabular}


Table 3 Effect on reliability of different number of genetic algorithm runs

\begin{tabular}{|c|c|c|c|c|c|c|c|}
\hline \multirow{2}{*}{ Frame } & UBC1 & UBC2 & UBC3 & UBC4 & FBC1 & FBC2 & FBC3 \\
\hline & \multicolumn{7}{|c|}{ (meanweight $_{1 \text { oruns }}-$-meanweight $\left._{30 \text { runs }}\right) /$ meanweight $_{30 \text { runs }}$} \\
\hline $\mathrm{A}(40 \mathrm{~m})$ & $0.02 \%$ & $0.39 \%$ & $0.13 \%$ & $-0.48 \%$ & $2.35 \%$ & $1.25 \%$ & $1.63 \%$ \\
\hline $\mathrm{B}(50 \mathrm{~m})$ & $0.00 \%$ & $0.20 \%$ & $0.00 \%$ & $0.22 \%$ & $-0.38 \%$ & $1.69 \%$ & $2.50 \%$ \\
\hline $\mathrm{C}(60 \mathrm{~m})$ & & & & & $0.93 \%$ & $0.39 \%$ & $4.03 \%$ \\
\hline
\end{tabular}

Table 4 Comparison with previous results in the literature

\begin{tabular}{|l|l|l|l|l|l|}
\hline \multirow{2}{*}{ Benchmark } & Researchers & Column sections & Rafter sections & Depth of haunch (m) & $\begin{array}{l}\text { Length of haunch } \\
(\mathrm{m})\end{array}$ \\
\hline \multirow{3}{*}{ Issa and Mohammad (2010) } & & & & & 2.45 \\
& Issa and Mohammad (2010) & $457 \times 152 \times 52$ & $406 \times 140 \times 46$ & 0.11 & 3.60 \\
\cline { 2 - 6 } & Phan et al. (2013) & $457 \times 152 \times 52$ & $356 \times 127 \times 33$ & 0.49 & 5.13 \\
\cline { 2 - 6 } & UBC3 & $457 \times 152 \times 52$ & $356 \times 127 \times 33$ & n/a & 4.20 \\
\hline \multirow{2}{*}{ Phan et al. (2013) } & Phan et al. (2013) & $610 \times 229 \times 113$ & $533 \times 210 \times 82$ & 0.515 & 4.99 \\
\cline { 2 - 6 } & UBC3 & $610 \times 229 \times 113$ & $533 \times 210 \times 82$ & n/a & \\
\hline
\end{tabular}


Table 5 Optimisation of Frames A \& B composed of universal beams

\begin{tabular}{|c|c|c|c|c|c|c|c|c|c|c|c|c|}
\hline \multirow[b]{2}{*}{ Case } & \multirow[b]{2}{*}{ Frame } & \multirow[b]{2}{*}{ Column section } & \multirow[b]{2}{*}{ Rafter section } & \multirow[b]{2}{*}{ Haunch section } & \multirow[b]{2}{*}{$H_{L}($ span \%) } & \multicolumn{3}{|l|}{ ULS } & \multicolumn{2}{|l|}{ LTB } & \multirow{2}{*}{$\begin{array}{l}\text { SLS } \\
\text { Max of } \\
g_{6 R} / g_{7 R}\end{array}$} & \multirow{2}{*}{$\begin{array}{l}\text { Frame } \\
\text { weight } \\
\left(\mathrm{kg} / \mathrm{m}^{2}\right)\end{array}$} \\
\hline & & & & & & $g_{3 C}$ & $g_{3 R}$ & $\mathrm{~g}_{3 \mathrm{H}}$ & $\begin{array}{l}\text { Max of } \\
g_{4 c / g_{5 c}}\end{array}$ & $\begin{array}{l}\text { Max of } \\
g_{4 R /} / g_{5 R}\end{array}$ & & \\
\hline \multirow{2}{*}{ UBC1 } & A & $838 \times 292 \times 176$ UB & $762 \times 267 \times 173$ UB & $762 \times 267 \times 173$ UB & $10.0 \%$ & 0.80 & 0.47 & 0.48 & 0.85 & 0.52 & 0.94 & 46.75 \\
\hline & $B$ & $1016 \times 305 \times 272$ UB & $1016 \times 305 \times 249$ UB & $1016 \times 305 \times 249$ UB & $10.0 \%$ & 0.74 & 0.47 & 0.45 & 0.78 & 0.49 & 0.97 & 68.07 \\
\hline \multirow{2}{*}{ UBC2 } & A & $914 \times 305 \times 201$ UB & $762 \times 267 \times 134$ UB & $610 \times 305 \times 179$ UB & $10.0 \%$ & 0.68 & 0.74 & 0.61 & 0.72 & 0.58 & 1.00 & 42.54 \\
\hline & $\mathrm{B}$ & $1016 \times 305 \times 272$ UB & $1016 \times 305 \times 249$ UB & $762 \times 267 \times 197$ UB & $10.0 \%$ & 0.74 & 0.57 & 0.46 & 0.78 & 0.49 & 0.99 & 67.10 \\
\hline \multirow{2}{*}{ UBC3 } & A & $914 \times 305 \times 201$ UB & $686 \times 254 \times 140$ UB & $686 \times 254 \times 140$ UB & $14.3 \%$ & 0.70 & 0.65 & 0.51 & 0.74 & 0.57 & 1.00 & 43.81 \\
\hline & $B$ & $1016 \times 305 \times 272$ UB & $1016 \times 305 \times 249$ UB & $1016 \times 305 \times 249$ UB & $7.6 \%$ & 0.72 & 0.51 & 0.51 & 0.77 & 0.50 & 1.00 & 67.12 \\
\hline \multirow{2}{*}{ UBC4 } & $A$ & $914 \times 305 \times 201$ UB & $762 \times 267 \times 134$ UB & $610 \times 305 \times 179$ UB & $14.1 \%$ & 0.68 & 0.74 & 0.61 & 0.72 & 0.58 & 1.00 & 42.52 \\
\hline & B & $1016 \times 305 \times 272$ UB & $1016 \times 305 \times 222$ UB & $838 \times 292 \times 226$ UB & $11.5 \%$ & 0.76 & 0.58 & 0.46 & 0.81 & 0.51 & 1.00 & 65.51 \\
\hline
\end{tabular}

Table 6 Optimisation of Frames A, B \& C composed of fabricated beams using $L_{c r}=1.5 \mathrm{~m}$

\begin{tabular}{|c|c|c|c|c|c|c|c|c|c|c|c|c|}
\hline \multirow[b]{2}{*}{ Case } & \multirow[b]{2}{*}{ Frame } & \multirow[b]{2}{*}{$\begin{array}{l}\text { Column section } \\
\text { dimensions }(\mathrm{mm})\end{array}$} & \multirow[b]{2}{*}{$\begin{array}{l}\text { Rafter section } \\
\text { dimensions }(\mathrm{mm})\end{array}$} & \multirow[b]{2}{*}{$\begin{array}{l}\text { Haunch section } \\
\text { dimensions }(\mathrm{mm})\end{array}$} & \multirow[b]{2}{*}{$\mathrm{H}_{\mathrm{L}}(\operatorname{span} \%)$} & \multicolumn{3}{|l|}{ ULS } & \multicolumn{2}{|l|}{ LTB } & \multirow{2}{*}{$\begin{array}{l}\text { SLS } \\
\text { Max of } \\
g_{6 R} / g_{7 R}\end{array}$} & \multirow{2}{*}{$\begin{array}{l}\text { Frame } \\
\text { weight } \\
\left(\mathrm{kg} / \mathrm{m}^{2}\right)\end{array}$} \\
\hline & & & & & & $g_{3 c}$ & $g_{3 R}$ & $g_{3 H}$ & $\begin{array}{l}\text { Max of } \\
g_{4 c / g_{5 c}}\end{array}$ & $\begin{array}{l}\text { Max of } \\
g_{4 R / g_{5 R}}\end{array}$ & & \\
\hline \multirow{3}{*}{ FBC1 } & A & $1336 \times 186 \times 177 \mathrm{FB}$ & $692 \times 186 \times 114 \mathrm{FB}$ & $692 \times 186 \times 114 \mathrm{FB}$ & $16.1 \%$ & 0.82 & 0.78 & 0.54 & 1.00 & 0.69 & 1.00 & 37.59 \\
\hline & $\mathrm{B}$ & $1708 \times 171 \times 273 \mathrm{FB}$ & $891 \times 171 \times 170 \mathrm{FB}$ & $891 \times 171 \times 170 \mathrm{FB}$ & $17.2 \%$ & 0.77 & 0.73 & 0.49 & 1.00 & 0.66 & 1.00 & 56.09 \\
\hline & $\mathrm{C}$ & $1893 \times 227 \times 365 \mathrm{FB}$ & $1110 \times 227 \times 243 \mathrm{FB}$ & $1110 \times 227 \times 243 \mathrm{FB}$ & $15.3 \%$ & 0.79 & 0.65 & 0.46 & 0.94 & 0.57 & 1.00 & 72.51 \\
\hline \multirow{3}{*}{$\mathrm{FBC2}$} & A & $1262 \times 204 \times 167 \mathrm{FB}$ & $784 \times 122 \times 120 \mathrm{FB}$ & $784 \times 122 \times 120 \mathrm{FB}$ & $12.6 \%$ & 0.82 & 0.75 & 0.63 & 0.96 & 0.88 & 0.98 & 37.04 \\
\hline & $\mathrm{B}$ & $1352 \times 272 \times 228 \mathrm{FB}$ & $1000 \times 89 \times 190 \mathrm{FB}$ & $1000 \times 89 \times 190 \mathrm{FB}$ & $15.4 \%$ & 0.89 & 0.61 & 0.49 & 0.94 & 0.91 & 0.99 & 55.47 \\
\hline & C & $1653 \times 398 \times 316 \mathrm{FB}$ & $1241 \times 125 \times 250 \mathrm{FB}$ & $1241 \times 125 \times 250 \mathrm{FB}$ & $15.8 \%$ & 0.83 & 0.61 & 0.44 & 0.83 & 0.82 & 1.00 & 70.49 \\
\hline \multirow{3}{*}{ FBC3 } & A & $965 \times 277 \times 143 \mathrm{FB}$ & $940 \times 182 \times 136 \mathrm{FB}$ & $302 \times 148 \times 103 \mathrm{FB}$ & $5.7 \%$ & 0.94 & 0.94 & 0.83 & 0.98 & 0.84 & 0.99 & 36.06 \\
\hline & $B$ & $1086 \times 385 \times 202 \mathrm{FB}$ & $1425 \times 159 \times 206 \mathrm{FB}$ & $231 \times 182 \times 127 \mathrm{FB}$ & $7.6 \%$ & 0.99 & 0.81 & 0.69 & 0.98 & 0.99 & 0.98 & 53.13 \\
\hline & C & $1530 \times 281 \times 280 \mathrm{FB}$ & $1544 \times 239 \times 268 \mathrm{FB}$ & $114 \times 509 \times 233 \mathrm{FB}$ & $4.3 \%$ & 0.93 & 0.94 & 0.84 & 0.98 & 0.68 & 0.97 & 66.21 \\
\hline
\end{tabular}


Table 7 Optimisation of Frames A, B \& C composed of fabricated beams using $L_{c r}=2.5 \mathrm{~m}$

\begin{tabular}{|c|c|c|c|c|c|c|c|c|c|c|c|c|}
\hline \multirow[b]{2}{*}{ Case } & \multirow[b]{2}{*}{ Frame } & \multirow{2}{*}{$\begin{array}{l}\text { Column section } \\
\text { dimensions }(\mathrm{mm})\end{array}$} & \multirow{2}{*}{$\begin{array}{l}\text { Rafter section } \\
\text { dimensions }(\mathrm{mm})\end{array}$} & \multirow{2}{*}{$\begin{array}{l}\text { Haunch section } \\
\text { dimensions }(\mathrm{mm})\end{array}$} & \multirow[b]{2}{*}{$H_{L}(\operatorname{span} \%)$} & \multicolumn{3}{|l|}{ ULS } & \multicolumn{2}{|l|}{ LTB } & \multirow{2}{*}{$\begin{array}{l}\text { SLS } \\
\text { Max of } \\
g_{6 R} / g_{7 R}\end{array}$} & \multirow{2}{*}{$\begin{array}{l}\text { Frame } \\
\text { weight } \\
\left(\mathrm{kg} / \mathrm{m}^{2}\right)\end{array}$} \\
\hline & & & & & & $g_{3 C}$ & $g_{3 R}$ & $\mathrm{~g}_{3 \mathrm{H}}$ & $\begin{array}{l}\text { Max of } \\
g_{4 c / g_{5 C}}\end{array}$ & $\begin{array}{l}\text { Max of } \\
g_{4 R / g_{5 R}}\end{array}$ & & \\
\hline \multirow{3}{*}{ FBC1 } & A & $1344 \times 232 \times 189 \mathrm{FB}$ & $708 \times 232 \times 124 \mathrm{FB}$ & $708 \times 232 \times 124 \mathrm{FB}$ & $10.7 \%$ & 0.71 & 0.74 & 0.73 & 0.98 & 0.75 & 1.00 & 39.26 \\
\hline & B & $1627 \times 251 \times 274 \mathrm{FB}$ & $888 \times 251 \times 182 \mathrm{FB}$ & $888 \times 251 \times 182$ FB & $14.1 \%$ & 0.75 & 0.68 & 0.53 & 1.00 & 0.68 & 1.00 & 57.59 \\
\hline & $\mathrm{C}$ & $1775 \times 324 \times 356 \mathrm{FB}$ & $1050 \times 324 \times 248 \mathrm{FB}$ & $1050 \times 324 \times 248 \mathrm{FB}$ & $16.7 \%$ & 0.80 & 0.65 & 0.43 & 0.96 & 0.56 & 1.00 & 73.78 \\
\hline \multirow{3}{*}{$\mathrm{FBC2}$} & A & $1139 \times 252 \times 174 \mathrm{FB}$ & $722 \times 167 \times 117 \mathrm{FB}$ & $722 \times 167 \times 117 \mathrm{FB}$ & $16.0 \%$ & 0.80 & 0.74 & 0.53 & 0.97 & 0.94 & 0.99 & 37.91 \\
\hline & B & $1493 \times 321 \times 256 \mathrm{FB}$ & $978 \times 167 \times 194 \mathrm{FB}$ & $978 \times 167 \times 194 \mathrm{FB}$ & $11.5 \%$ & 0.75 & 0.66 & 0.60 & 0.87 & 0.89 & 0.98 & 57.49 \\
\hline & C & $1710 \times 295 \times 324 \mathrm{FB}$ & $1126 \times 129 \times 254 \mathrm{FB}$ & $1126 \times 129 \times 254 \mathrm{FB}$ & $14.7 \%$ & 0.80 & 0.64 & 0.46 & 0.96 & 0.98 & 1.00 & 71.20 \\
\hline \multirow{3}{*}{ FBC3 } & A & $986 \times 321 \times 156$ FB & $917 \times 161 \times 133 \mathrm{FB}$ & $395 \times 182 \times 128 \mathrm{FB}$ & $5.2 \%$ & 0.84 & 0.89 & 0.75 & 0.94 & 0.99 & 0.97 & 36.93 \\
\hline & $B$ & $1299 \times 333 \times 213 \mathrm{FB}$ & $1253 \times 197 \times 207 \mathrm{FB}$ & $290 \times 219 \times 111 \mathrm{FB}$ & $4.1 \%$ & 0.87 & 0.87 & 0.81 & 1.00 & 0.93 & 0.95 & 52.92 \\
\hline & C & $1395 \times 395 \times 301 \mathrm{FB}$ & $1549 \times 213 \times 266$ FB & $168 \times 355 \times 176 \mathrm{FB}$ & $4.8 \%$ & 0.86 & 0.92 & 0.82 & 0.92 & 0.92 & 0.98 & 67.10 \\
\hline
\end{tabular}

Table 8 Optimal designs with serviceability limits removed

\begin{tabular}{|c|c|c|c|c|c|c|c|c|c|c|c|}
\hline \multirow[b]{2}{*}{ Case } & \multirow[b]{2}{*}{ Frame } & \multirow{2}{*}{$\begin{array}{l}\text { Column section } \\
\text { dimensions }(\mathrm{mm})\end{array}$} & \multirow{2}{*}{$\begin{array}{l}\text { Rafter section } \\
\text { dimensions ( } \mathrm{mm})\end{array}$} & \multirow{2}{*}{$\begin{array}{l}\text { Haunch section } \\
\text { dimensions }(\mathrm{mm})\end{array}$} & \multirow[b]{2}{*}{$\mathrm{H}_{\mathrm{L}}(\operatorname{span} \%)$} & \multicolumn{3}{|l|}{ ULS } & \multicolumn{2}{|l|}{ LTB } & \multirow{2}{*}{$\begin{array}{l}\text { Frame weight } \\
\left(\mathrm{kg} / \mathrm{m}^{2}\right)\end{array}$} \\
\hline & & & & & & $g_{3 c}$ & $g_{3 R}$ & $g_{3 H}$ & $\begin{array}{l}\text { Max of } \\
g_{4 c / g_{5 c}}\end{array}$ & $\begin{array}{l}\text { Max of } \\
g_{4 R / g_{5 R}}\end{array}$ & \\
\hline \multirow{2}{*}{ UBC1 } & $A$ & $610 \times 229 \times 113$ UB & $610 \times 229 \times 113$ UB & $610 \times 229 \times 113$ UB & $10 \%$ & 0.89 & 0.91 & 0.86 & 0.93 & 0.77 & 35.47 \\
\hline & $\mathrm{B}$ & $686 \times 254 \times 152$ UB & $686 \times 254 \times 152$ UB & $686 \times 254 \times 152$ UB & $10 \%$ & 0.95 & 0.99 & 0.96 & 0.99 & 0.80 & 46.03 \\
\hline \multirow{3}{*}{ FBC1 } & $A$ & $533 \times 337 \times 110 \mathrm{FB}$ & $533 \times 337 \times 110 \mathrm{FB}$ & $533 \times 337 \times 110 \mathrm{FB}$ & $12.1 \%$ & 0.89 & 0.99 & 0.99 & 1.00 & 0.85 & 34.57 \\
\hline & $B$ & $671 \times 310 \times 148 \mathrm{FB}$ & $671 \times 310 \times 148 \mathrm{FB}$ & $671 \times 310 \times 148 \mathrm{FB}$ & $10.9 \%$ & 0.83 & 0.99 & 0.99 & 1.00 & 0.85 & 47.01 \\
\hline & C & $760 \times 374 \times 197 \mathrm{FB}$ & $760 \times 374 \times 197 \mathrm{FB}$ & $760 \times 374 \times 197$ FB & $12.3 \%$ & 0.91 & 1.00 & 0.88 & 1.00 & 0.76 & 57.50 \\
\hline
\end{tabular}

